\title{
Uncovering changes in university teachers' professional networks during an instructional development program
}

\author{
Sara Van Waes ${ }^{\mathrm{a}, *}$, Piet Van den Bossche ${ }^{\mathrm{b}, \mathrm{c}}$, Nienke M. Moolenaar ${ }^{\mathrm{d}}$, Ann Stes ${ }^{\mathrm{a}}$, \\ Peter Van Petegem ${ }^{\mathrm{b}, \mathrm{a}}$ \\ ${ }^{a}$ Centre for Excellence in Higher Education, University of Antwerp, Venusstraat 35, 2000 Antwerp, Belgium \\ ${ }^{\mathrm{b}}$ Institute for Education and Information Sciences, University of Antwerp, Venusstraat 35, 2000 Antwerp, Belgium \\ ${ }^{\mathrm{c}}$ Department of Educational Research and Development, Maastricht University, P.O. Box 616, 6200 MD Maastricht, The Netherlands \\ ${ }^{\mathrm{d}}$ Department of Education, Utrecht University, Heidelberglaan 1, P.O. Box 80.140, 3508 TC Utrecht, The Netherlands
}

\section{A R T I C L E I N F O}

\section{Article history:}

Received 30 July 2014

Received in revised form 28 January 2015

Accepted 18 February 2015

Available online xxx

\section{Keywords:}

Higher education

Instructional development program

Faculty development

Social network

Longitudinal

Personal network

\begin{abstract}
A B S T R A C T
This study examined (1) the extent to which university teachers' networks changed while they participated in an instructional development program, (2) which mechanisms supported or constrained network change, and (3) the extent to which value was created through networks. Longitudinal social network data combined with follow-up interviews were collected over a 2-year time frame from 16 university teachers participating in an instructional development program. Results showed that teachers' networks increased and remained relatively stable after the program had finished. Several underlying mechanisms for network change throughout the program were identified (e.g., departmental culture, network intentionality, trust). Moreover, both expressive (e.g., venting) and instrumental value (e.g., getting ideas or feedback) were created through teachers' networks. This research contributes to our understanding of the social side of instructional development.
\end{abstract}

(c) 2015 Elsevier Ltd. All rights reserved.

\section{Introduction}

Traditionally, university teachers begin teaching in higher education with little or no formal training. Being an expert in the content field is assumed to be a sufficient condition to teach others (Denicolo \& Becker, 2013). Over the past two decades, improving university teaching standards has been the driver of interest in academic development internationally (Baume, 2006; Devlin \& Samarawickrema, 2010). To enhance the quality of teaching and learning, instructional development programs have emerged in higher education institutions around the globe. Instructional development is a type of development that explicitly aims to develop faculty members in their role as a teacher (Centra, 1989; Taylor \& Rege Colet, 2010). Programs for instructional development are those formal programs that induct and develop university teachers with the aim of fostering and supporting the

\footnotetext{
* Corresponding author. Tel.: +32 326548 29; fax: +32 32654501.

E-mail addresses: Sara.VanWaes@uantwerpen.be (S. Van Waes), Piet.VandenBossche@uantwerpen.be (P. Van den Bossche), N.M.Moolenaar@uu.nl (N.M. Moolenaar), Ann.Stes@uantwerpen.be (A. Stes), Peter.VanPetegem@uantwerpen.be (P. Van Petegem).
}

quality of teaching and learning in the university' (Hicks, Smigiel, Wilson, \& Luzeckyj, 2010, p. 18).

While most studies into the impact of instructional development regard instructional development as an individual endeavor, by examining teachers' attitudes (e.g., Postareff, Lindblom-Ylänne, \& Nevgi, 2007), teachers' conceptions (e.g., Hubball, Collins, \& Pratt, 2005), teachers' knowledge (e.g., Howland \& Wedman, 2004), teachers' skills (e.g., Stepp-Greany, 2004) and teachers' behavior (e.g., Stes, Coertjens, \& Van Petegem, 2013), the social context in which teaching occurs is often overlooked (Van Waes, Van den Bossche, Moolenaar, De Maeyer, \& Van Petegem, 2015; Rienties \& Kinchin, 2014). Recent work on faculty's communities of practice and learning communities emphasized that university teaching is both individually constructed as well as socially influenced (Anderson \& McCune, 2013; Furco \& Moely, 2012). Multiple studies recognize the importance of informal, situated social learning in shaping thinking and practice (Mathieson, 2011; Stes, Clement, \& Van Petegem, 2007; Warhurst, 2008).

However, in higher education, issues of privacy, autonomy, and even isolation of faculty have been quite prominent (Cox, 2004; Johnsrud \& Heck, 1998). Faculty members' research work often involves elaborate and strong networks of collaboration and support (Baker \& Zeyferrell, 1984; Gizir \& Simsek, 2005), but 
university teaching remains a relatively solitary business (Ramsden, 1998). In contrast to other professions, teachers often lack continuous interaction with colleagues that could help them grow more fully into the demands of the teaching profession (Little, 1990). In an essay, Palmer (1999) argued that without collegial socialization a privatization of teaching creates institutional incompetence. The outcome of privatized teaching is that performance becomes more conservative, and few stray far from the silent consensus of what 'works', even when it does not work. Prior research also reveals that feelings of disconnectedness and loneliness have consistently been expressed by faculty (Barnes, Agago, \& Coombs, 1998; Boice, 1992; Schoenfeld \& Magnan, 1992). Work by Fouche (2006) showed that feelings of isolation can be significantly curbed by regular contact and collaboration amongst colleagues, and regular training (see also Lockwood \& Latchem, 2004; Schrum \& Ohler, 2005).

In recent years, the 'social side' of instructional development programs is increasingly recognized. The benefits of socially coconstructing and sharing information in instructional development programs are emphasized, as well as the novelty of encountering different teaching cultures and working practices (Gale, 2011; Stewart, 2014). Moreover, the impact of instructional development programs is influenced by interacting with colleagues and exchanging experiences (Postareff et al., 2007; Stes, MinLeliveld, Gijbels, \& Van Petegem, 2010).

Yet, to date relatively little is known about the extent to which university teachers actually engage with colleagues and others during and beyond instructional development programs (Rienties \& Kinchin, 2014). There is limited research on how collegial interactions might matter in instructional development programs, and under which conditions collegial interaction can support instructional development in higher education. This paper argues that a social network perspective may offer a new and unique perspective on interactions between university teachers. Social network theory offers a valuable lens and tools to capture the interactions or networks of educators (Carolan, 2014; Daly, 2010). The current study draws upon longitudinal social network data, triangulated with in-depth interview data, collected over the course of an instructional development program. Our aim is to further uncover the social side of instructional development programs.

\section{A social take on instructional development}

Studies evaluating the impact of instructional development initiatives have acknowledged the role of collegial interactions within and outside the instructional development initiative. Participating in an instructional development program has shown to enhance collegial interactions in departments, and teachers discussed their teaching practice with colleagues more often (Skeff, Stratos, Bergen, \& Regula, 1998). Moreover, they shared more information and teaching material among colleagues after the program (Harnish \& Wild, 1993), interdisciplinary collegiality tended to increase (Fidler, Neururer-Rotholz, \& Richardson, 1999; Pololi et al., 2001), and a preference for peer collaboration was found (McDonough, 2006). However, most of these findings arose as a 'side-effect' while examining the impact of instructional development. Few studies have actually carried out an in-depth study on how collegial interactions might matter and evolve during instructional development programs, and which mechanisms may support or inhibit these interactions. Social network theory provides a useful framework to examine university teachers' interactions during instructional development programs.

A social network perspective on instructional development programs

Recent work in the field of learning and professional development has demonstrated the potential of adopting a social network perspective to study the transfer and impact of development programs (Hatala, 2006; Van den Bossche \& Segers, 2013). The main stance of social network theory is that individuals' behavior and performance are significantly affected by the way they are tied into a larger web of social connections (Carrington, Scott, \& Wasserman, 2005). In social network theory the people or actors in the network are termed 'nodes', and the relations connecting them are 'ties' (Wasserman \& Faust, 1994). Social network theory has proven a valuable lens to capture the interactions or networks of educators (Moolenaar, 2012), and provides methods to track network change in a fine-grained way (Snijders, 2005). Until now, previous methods have not been able to map (changes in) interactions, which is an important first step in further theorizing the role of interactions for instructional development in higher education.

Recently, scholars started to explore faculty members' teaching networks (Jippes et al., 2013; Pataraia, Margaryan, Falconer, \& Littlejohn, 2013; Van Waes et al., 2015). Within the context of higher education, relatively little is known about how collegial interactions might shape the effects of instructional development programs. To our knowledge, only three studies have examined university teachers' social networks in instructional development programs. Moses, Skinner, Hicks, and O'Sullivan (2009) conducted interviews with 43 participants at the end of an instructional development program in the health sciences. Their findings showed that the number of connections between participants increased from 6 to 36 over the course of the program, and that participants increasingly connected to faculty in educational central services (from 6 to 70 connections). Rienties and Kinchin (2014) studied networks between participants and networks with people outside the program. Their study of 54 participants showed that participants developed on average four relations with other participants, and three to four relations with people outside the program. Network relations were primarily formed according to participants' departments and the group division in the program. Triangulation with a qualitative free-response exercise showed 'friendship' and 'persistence of initial groupings' as key emerging themes for the formation of relations. Jippes et al. (2013) studied participants' networks outside the program, i.e., departmental networks of clinical supervisors participating in a 2-day medical education program on a specific innovation. Their findings showed that adoption of the innovation was related to the connectedness of the participants in their departmental network.

These studies offer insight into the potential of social networks in instructional development programs. However, as they have cross-sectional designs, they provide limited understanding of the process of network change over the course of instructional development programs. Research has shown that social networks are dynamic and may evolve over time (Kilduff \& Tsai, 2003; Snijders, 2005). Recent scholarship also criticizes that most studies examining instructional development only collect data once, upon completion of the program, instead of over the course of the program and longer after completion (Rienties \& Kinchin, 2014; Stewart, 2014). The current study adds to earlier findings by tracking social networks over a 2-year timeframe, over the course of a 16-month long instructional development program, thereby deepening insight into network change. Moreover, it examines mechanisms underlying changes in networks.

\section{Underlying mechanisms for network change}

Different mechanisms may underlie change in teachers' networks. Networks are often considered positive relations. However, they can also comprise negative relations or constraining mechanisms, termed 'negative or difficult ties' (Everett \& Borgatti, 2014; Labianca, 2014). Therefore, we explored mechanisms that supported and constrained network change over the course of an 
instructional development program. Research on these mechanisms in instructional development research in higher education is limited, therefore we draw on network change and higher education research in general.

A mechanism that has recently gained increased attention in the scholarship of network change is 'network intentionality', meaning the extent to which an educator is intentional in connecting and interacting with others (Cohen, Klein, Daly, \& Finnigan, 2011; Moolenaar et al., 2014). For example, a university teacher might be intentional about actively seeking information or advice from others, or might like or dislike connecting with others about teaching. This suggests that individuals have agency in starting new interactions, staying connected with people, or dissolving certain relations (Burt \& Ronchi, 2007). Within the context of instructional development programs participants are encouraged to look for information, advice and research evidence to enhance their teaching. The extent to which they are intentional about their collegial interactions (e.g., actively seek out people to interact with about their teaching practice, or go to teaching experts for advice) might influence this. Hence, network intentionality might be an important mechanism underlying network change over the course of instructional development programs.

In higher education literature the role of university teachers departmental culture is recurrently emphasized in studies examining conditions of instructional development programs. Departmental cultures may constrain or facilitate the exchange within a program depending on departmental values of and attitudes toward the (relative) merits of teaching versus research (Rienties \& Kinchin, 2014). They can limit teachers' opportunities to experiment with new practices in their courses or to engage in deep conversations with colleagues about the problems they face implementing new practices (Coburn \& Russell, 2008; Gallucci, 2008). Trowler and Cooper (2002) introduced the concept of 'teaching and learning regimes' (TLR's), i.e., a constellation of rules, assumptions, practices, and relations related to teaching and learning issues in higher education. The success of an instructional development program depends on the compatibility between the TLR's of the program and the departmental teaching context to which the teacher subsequently returns (Mathieson, 2011). TLR's are considered socially rooted and influenced by social networks (Roxå, Mårtensson, \& Alveteg, 2011).

This study will examine network intentionality and departmental culture as possible mechanisms underlying network change during an instructional development program. Moreover, as little is known about mechanisms supporting or constraining network change during instructional development programs, this study will also openly explore other mechanisms.

\section{The value created through networks in instructional development programs}

Having collegial interactions about teaching does not automatically contribute to improved instructional development. Or differently put, simply sharing ideas, experiences or resources does not necessarily mean that value is created. Few studies have closely examined the value of interactions within the context of instructional development programs. Some authors have indicated that participants within an instructional development program found exchanging experiences with participants from other departments helpful (Gale, 2011; Postareff et al., 2007; Stewart, 2014). Teachers also felt more capable of expressing their opinion in discussions about education after instructional development (Stes et al., 2007). This study will further explore how teachers perceive the value created through their network as they participate in an instructional development program. A useful dimension of social relationships that has become common practice in social network research, is the distinction between instrumental and expressive relations (Ibarra, 1993, 1995). Instrumental relations encompass social interactions that are ultimately aimed at achieving organizational goals, such as work related advice or collaboration. Expressive relations are characterized by an affective component, such as personal support and friendship. These dimensions will be used as a framework to explore the value created in teachers' networks.

\section{The present study}

A social network perspective was used to examine the interactions of university teachers over the course of a 16-month instructional development program. Since our data were collected over four measurement waves, changed systematically over time, and a sensible metric for clocking time was used (Singer \& Willet, 2003), we will continue by describing this study as a longitudinal study, amenable to the analysis of network change (Feld, Suitor, \& Gartner Hoegh, 2007). Longitudinally collected network data allowed us to grasp networks over time and yielded further insights into the social side of instructional development. Additional qualitative data provided insight into underlying mechanisms of network change and into the value created by networks as they participate in an instructional development program. Qualitative network studies are considered powerful in unearthing the social complexity that occurs in social networks as they change over time (Coburn, Russell, Kaufman, \& Stein, 2012; Fuhse \& Mützel, 2011). Specifically, this study was guided by the following research questions:

- RQ1: To what extent do university teachers' networks change while they participate in an instructional development program? - RQ2: Which mechanisms support or constrain changes in university teachers' networks while they participate in an instructional development program?

- RQ3: To what extent is value created through networks while they participate in an instructional development program?

\section{Method}

\section{Setting}

At a mid-sized university in Belgium, novice university teachers (i.e., instructors appointed as lecturers or assistant lecturers during the last 7 years) can participate voluntarily in a 16-month instructional development program. Course cohorts typically consist of 20-25 participants. The central aim of the program is to gear their teaching practice toward the concept of competencebased and student-activating teaching as embraced by university management. It is not an explicit aim of the instructional development program to change teachers' networks. The program starts off with a 2-day collective start with sessions on the five key topics of the program: (1) developing a course, (2) teaching a course, (3) assessing students, (4) evaluating a course, and (5) participating in curriculum development. At the end of the collective start, the participants individually write a teaching project plan, aligning their own goals with the five key topics of the program. Participants with similar project plans are grouped together, which creates four small, interdisciplinary groups of four to five teachers. Each group is assigned a tutor who provides individual feedback on the teaching project over the course of the program. The feedback is provided both individually (mostly by email) as well as face-to-face during four small-group meetings. During these meetings participants are expected to provide 
feedback on each other's teaching projects as well (i.e., as critical friends). Attending the meetings (the collective start and smallgroup meetings) and working on the teaching project plan involves minimally $150 \mathrm{~h}$ of workload, spread over a period of 16 months. At the end of the program, the participants present and defend their teaching project for an assessment committee, consisting of their tutor, the chair of education or another senior colleague, and an expert in the domain of education. After completion, participants receive a teaching qualification certificate when they have realized their starting goals and have met the evaluation criteria for the five main topics.

\section{Participants}

A total of 22 teachers took part in the present study. They enrolled in the above described instructional development program. Six of them quit the program after the first data collection wave due to new job opportunities, maternity leave or high workload. Of the remaining 16 teachers full network data were collected. Of these 16 teachers, seven belonged to a 'soft' discipline (e.g., history or political sciences), and nine to a 'hard' discipline (e.g., chemistry or medicine). Of the 16 teachers, 12 were male, which is considered a representative sample as only $20 \%$ of university teachers are female in the university where the program took place. Regarding academic status, most participants in our study were lecturers $(n=11)$. Assistant lecturers were less well represented $(n=4)$. One participant was senior lecturer. On average, the participants were 40 years old $(S D=7.62)$, and they had an average teaching experience of 8 years $(S D=6$; this includes years as teaching assistant). All teachers combined a teaching and research appointment; eight teachers indicated that they spent equal time on teaching and research, two indicated more emphasis on teaching, and six teachers spent more time on research than teaching.

\section{Instruments and procedure}

Extensive network and qualitative data were gathered longitudinally over a 2-year time-frame. Network questionnaires from four measurement moments were triangulated with in-depth interviews.

Network questionnaires were administered to gain insight into the dynamics and changes in the teachers' networks over the course of an instructional development program (RQ1). Network questionnaires are commonly used sociometric instruments in the field of network research (Carolan, 2014). They contain a central question that generates names (e.g., 'who are your friends?', or in this study: 'who do you communicate with about your teaching practice?'). Follow-up questions further inquire about the attributes of these people (e.g., age, department) and about relational characteristics (e.g., duration of the relation).

An identical network questionnaire was administered four times over a period of 20 months (Fig. 1), distributed by internal mail. The measurement moments were planned as follows: T1 took place right before the start of instructional development, T2 was the deadline for the formative submission of the teaching project, T3 was the final submission moment, and T4 was 6 months after the final submission of the project. Taking part in research was considered an explicit expectation of participating in the instructional development program. A response rate of $100 \%$ was obtained.

The central open-ended question in the network questionnaire was: "Write down the names of the people you communicate with about your teaching practice. This includes talks/calls/e-mails about preparing and teaching courses, teaching methods, student guidance, student assessment, thesis students and student evaluations.' We specified that we were not looking for administrative or legal discussions about education, and we set a clear time frame (the last 6 months) in order to gain insight into their current networks. We also indicated that the number of people ('alters') could be low or high depending on the teacher's specific situation, and people from within or outside the university could be included. Participants were asked to indicate whether the people they wrote down were from same or different departments, from different universities, or other (e.g., friends or family). At T2 and subsequent measurements, an overview of the alters listed at the previous measurement moment was provided for every teacher individually. This overview served as a reminder to prevent measurement error (e.g., 'new' or 'lost' relations due to forgetfulness). Every time the teachers were asked to update their networks by indicating with whom they still interacted, which interactions were new, and which connections were lost over time. Additionally, for every alter in teachers' networks the question was asked whether they had discussed their teaching project and the instructional development program. This network design allowed us to grasp the collegial interactions of teachers over the course of an instructional development program.

In-depth interviews were conducted 6 months after the last network questionnaire (Fig. 1) to gain insight into mechanisms underlying network change over the course of the instructional development program (RQ2), and to explore how teachers perceived the value created through their networks (RQ3). Based on analyses of the network questionnaire, five teachers with different profiles of network change were selected for interview (Table 1). The profiles were selected based on network size before and after instructional development (i.e., number of people in the network), and on the stability or change in the network during instructional development. We selected one isolated network, two stable networks (small stable and average stable), and two networks that showed clear change over the course of the program as they had many or the most new and lost ties (flexible and expansive). We anticipated that by investigating different profiles of network change, possible mechanisms could be uncovered that might support or constrain network change, as well as varying perceptions on the value of interactions when participating in an instructional development program.

For the interview, we used four network maps visualizing the participant's network change (T1-T4). Visualizations were made based on the network questionnaires (see Appendix A for an example), and following the mapping technique by Hogan,

$\begin{array}{lll}\mathrm{T} 1 & \mathrm{~T} 2 & \mathrm{~T} 3\end{array}$

T3

$\mathrm{T} 4$

T5

$\begin{array}{llll}\text { Before program } & \text { Midway program } \quad \text { End program } \quad \text { After program }\end{array}$

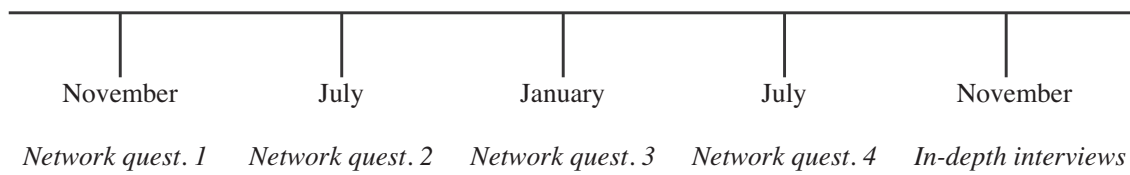

Fig. 1. Timing data collection. 
Table 1

Selection of five interviewed teachers based on network change.

\begin{tabular}{|c|c|c|c|c|c|}
\hline & $\begin{array}{l}\text { Isaac } \\
\text { Isolated }\end{array}$ & $\begin{array}{l}\text { Eliah } \\
\text { Small stable }\end{array}$ & $\begin{array}{l}\text { Joshua } \\
\text { Average stable }\end{array}$ & $\begin{array}{l}\text { Rose } \\
\text { Flexible }\end{array}$ & $\begin{array}{l}\text { Roxanne } \\
\text { Expansive }\end{array}$ \\
\hline Network size T1 & No relations & Small & Average & Average & Large \\
\hline Network size T4 & No relations & Small & Average & Large & Larger \\
\hline Network change $\mathrm{T} 2-\mathrm{T} 3$ & Most lost and kept ties & Stable & Stable & $\begin{array}{l}\text { Most lost ties } \\
\text { Many new ties }\end{array}$ & Most kept ties \\
\hline Ties on program ${ }^{a}$ & No & Few & Average & Many & Many \\
\hline
\end{tabular}

a Indicates with whom in their teaching network they have discussed their teaching project and the instructional development program. Note. Network size and change are indicated relative to the networks of the other teachers in the program.

Carrasco, and Wellman (2007) adapted by Van Waes et al. (2015). A semi-structured interview guide (Appendix B) probed for mechanisms underlying change in teachers' networks over the course of the instructional development program, such as reasons for new/ lost/kept persons, departmental culture, and network intentionality (RQ2); as well as for the value created through interactions while participating in the instructional development program (RQ3). Interviews lasted 40-120 min, depending on the size of and change in the networks. Interviews were recorded and transcribed verbatim.

\section{Analysis}

Network questionnaires. E-net (Halgin \& Borgatti, 2012) was used to generate the descriptive statistics of network change from T1 to T4. E-net is a software package designed for the analysis of ego-networks. An ego-network design involves sampling a collection of unrelated respondents ('egos') and asking them about the people in their lives ('alters'). The relations that an ego has with alters are 'ties'. The ego-network approach allowed us to track the extent to which individual teachers' networks changed over the course of an instructional development program. Networks maps were generated using UCINET version 6.512 (Borgatti, Everett, \& Freeman, 2002) to visualize network change of all teachers over the course of the instructional development program. Change and stability ratios were calculated for each teacher to grasp network change or stability over time.

Interviews. We examined underlying mechanisms of network change (RQ2) and value created through networks (RQ3) by openly coding the transcripts for emerging themes. In a next step, axial coding was applied through multiple rounds of analysis using the constant comparison method (Strauss \& Corbin, 1990). Peer debriefing was used to examine the emerged codes, and to further identify and categorize mechanisms supporting and constraining network change, and value created through networks.

\section{Results}

Change in university teachers' networks while participating in an instructional development program (RQ1)

Over the course of the study, the 16 university teachers communicated in total with 138 unique persons about their teaching practice, which resulted in 474 teaching relations (over four measurement moments). These are visualized in four network maps, one for each measurement moment (Figs. 2-5). The colors of the dots or 'nodes' in the maps represent the participants (black circles), the people guiding the program, e.g., the tutors and
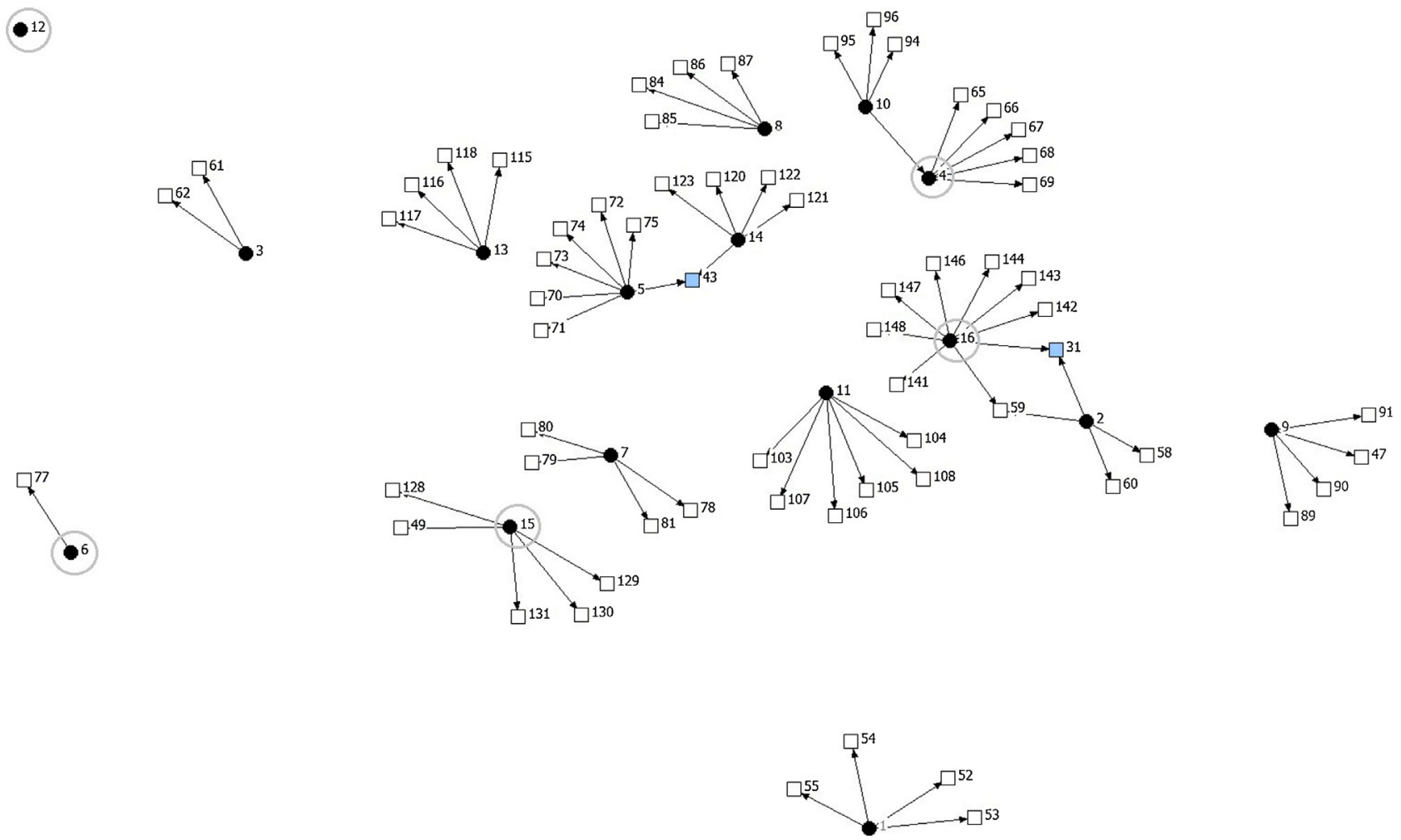

Fig. 2. Networks before the instructional development program (T1). Note. The participants selected for interview are encircled. 

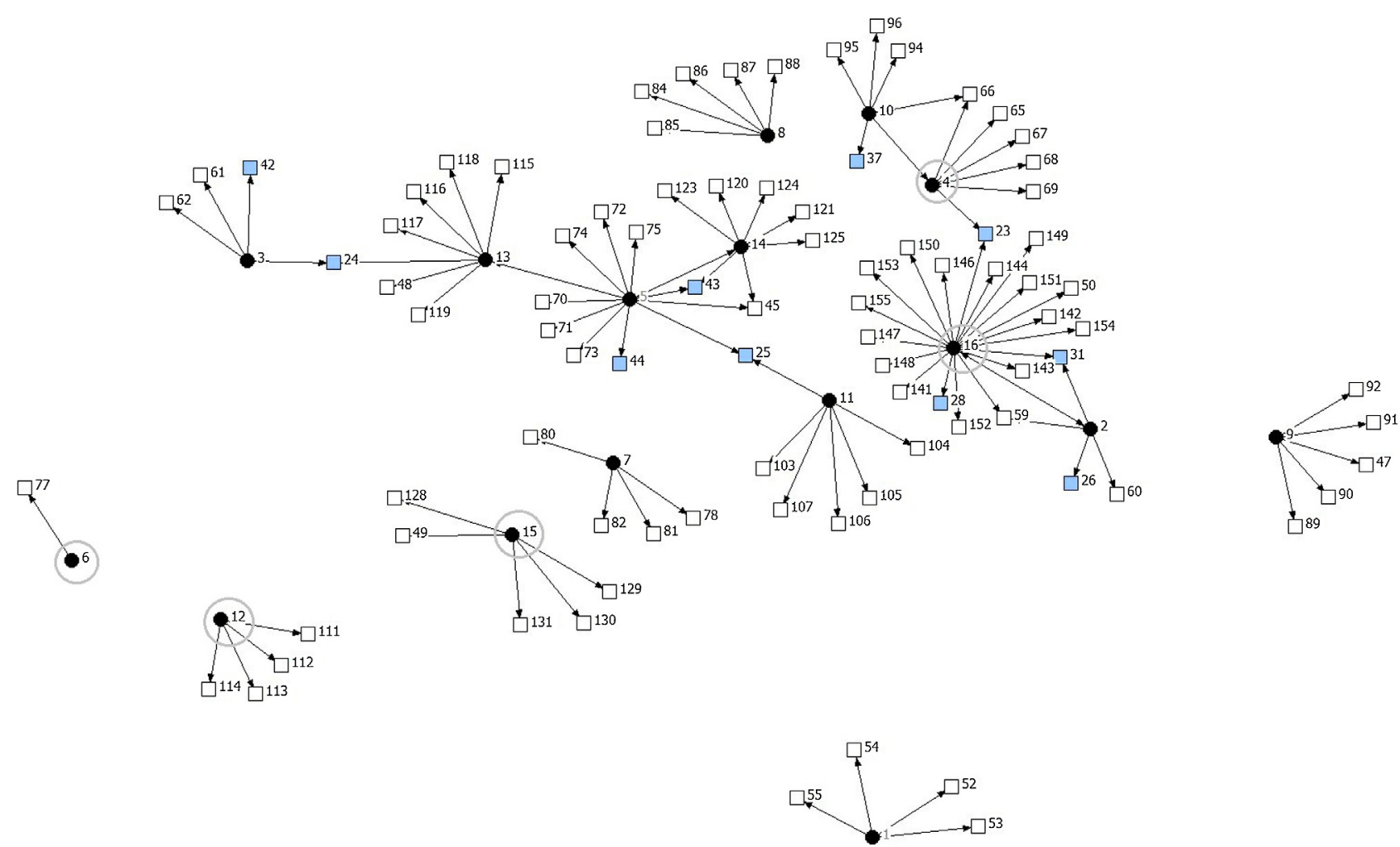

Fig. 3. Networks midway the instructional development program (T2). Note. The participants selected for interview are circled.

members of the assessment committee (gray squares), and the people outside the program (white squares). The arrows indicate the direction of the relation. Arrows always start from the participants as we only considered outgoing relations given the scope of first research question.
Three main take-ways can be deduced from the visualizations. First, the network clearly grew as the program evolved and remained stable after the program has finished. The participants increasingly connected to the people guiding the program, who occupied quite central positions in the network as they connected

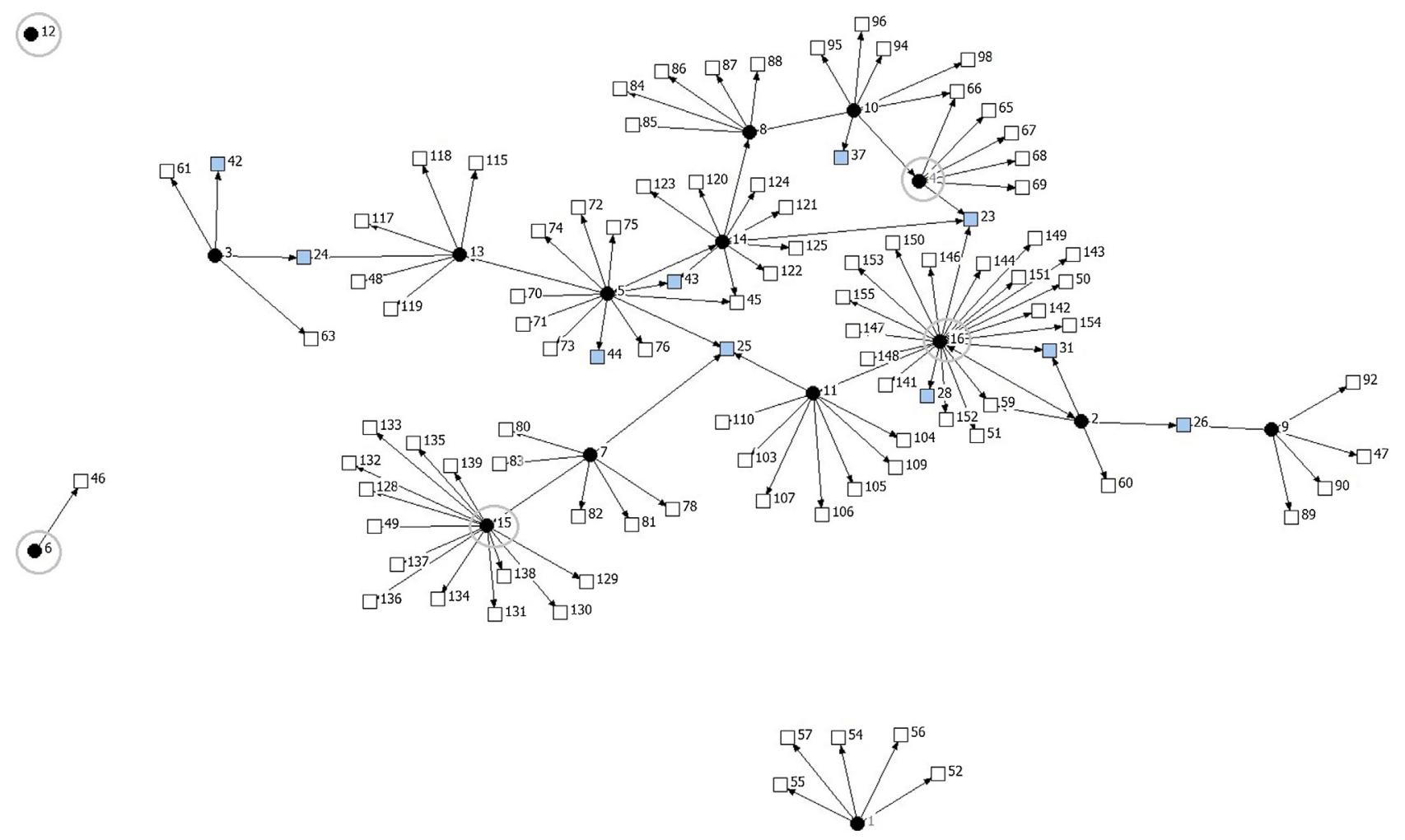

Fig. 4. Networks at the end of instructional development program (T3). Note. The participants selected for interview are encircled.

Please cite this article in press as: S. Van Waes, et al.. Uncovering changes in university teachers' professional networks during an instructional development program. Studies in Educational Evaluation (2015), http://dx.doi.org/10.1016/j.stueduc.2015.02.003 

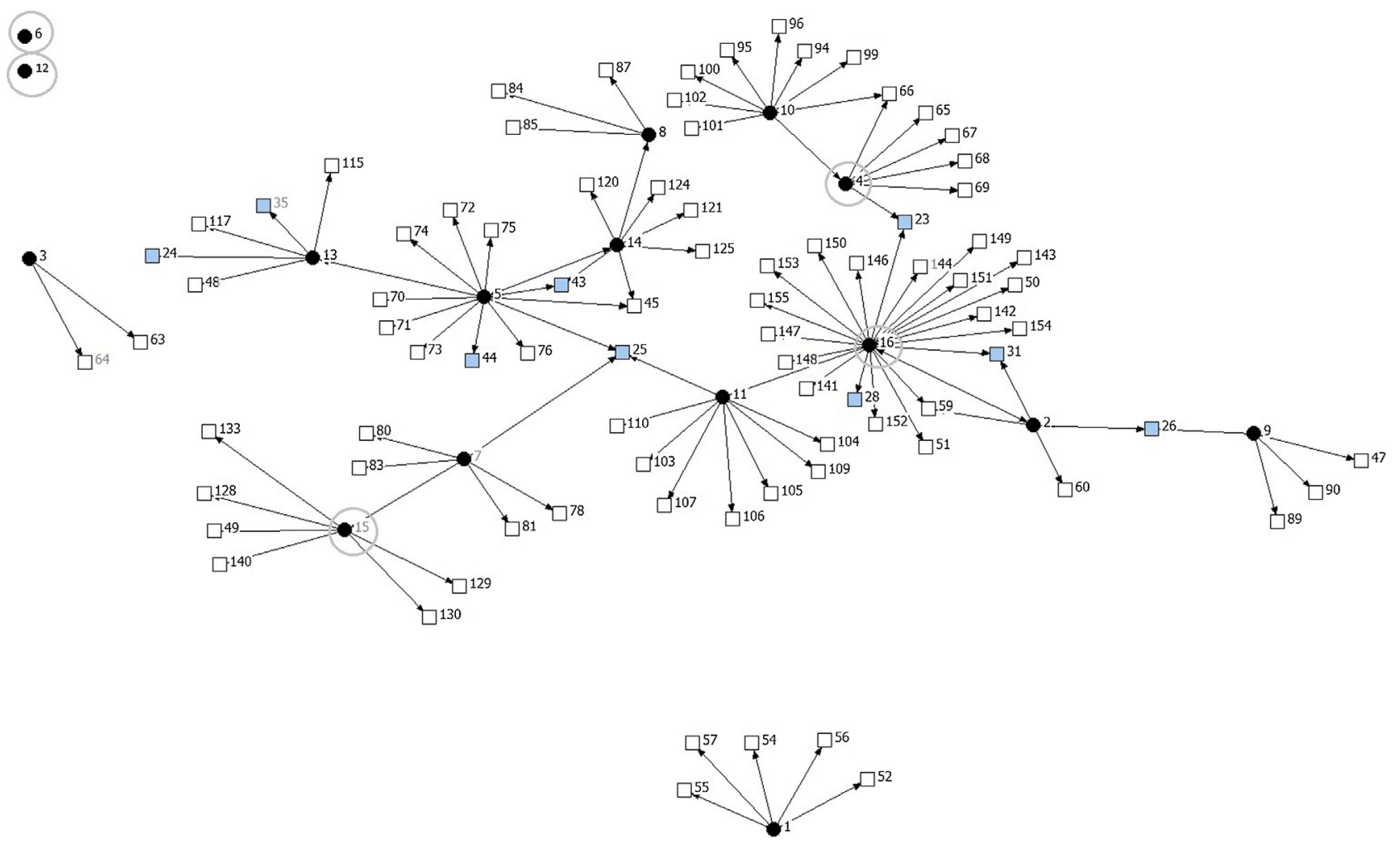

Fig. 5. Networks after the instructional development program (T4). Note. The participants selected for interview are encircled.

otherwise unconnected participants (i.e., 'brokers'). Second, some participants were on the outer fringe of the network and stayed isolated over the course of the program, especially participants 6 and 12. Participant 3 was quite isolated at the start of the program, but connected to other participants and people in educational central services as the program progressed. Third, overall, the network was relatively fragmented. The distance between several participants remained large, meaning that teaching resources (e.g., information, advice) did not spread easily in this network. Fragmentation decreased as the program evolved; leaving only participants 1, 3, 6 and 12 disconnected.

Network visualizations provide a solid first impression of how the teachers' networks changed over the course of the program. However, additional measures of network change are helpful in determining the actual changes in participants' networks change over the course of the program, such as the formation of new ties, the loss of ties, and the retention of existing ties. This is termed 'tie churn' (Sasovova, Mehra, Borgatti, \& Schippers, 2010). Table 2 presents the number of new, lost and kept ties.

Teachers' networks clearly expanded over the course of the program, from 4.25 relations on average to 7.31 relations. Most change occurred between $\mathrm{T} 1(M=4.25)$ and $\mathrm{T} 2(M=6.38)$. The increase in interactions persisted after the program had finished $(M=6.38)$. Overall, the standard deviation increased as the program progressed (except for 'new ties'), which shows that there was increasing variation among teachers in the number of ties and their tie change over time. Finally, teachers explicitly discussed their teaching project and the instructional development program with almost everyone in their network (cf. 'ties on program').

Table 3 shows the descriptive statistics of teachers' relations within and outside the program. On average, participants had 0.31 relations to people involved in the program (i.e., instructors, other participants and members of the assessment committee) before the start of the program (T1), which slightly increased to 1.69 relations at the end of the program (T3). Since the members of the assessment committee were the chairs of the educational board in participants' department, some of the participants were already discussing their teaching practice with these persons before the start of the program. Participants connected to remarkably few other participants over the course of the program. Eleven teachers did not discuss their teaching practice with other participants over the course of the program.

Not only did teachers' networks within the program grow, their network outside the program increased on average from 3.94 to

Table 2

Descriptive statistics of overall network change.

\begin{tabular}{|c|c|c|c|c|c|c|c|c|c|c|c|c|c|c|c|c|}
\hline & \multicolumn{4}{|c|}{$\begin{array}{l}\text { T1 } \\
\text { Before program }\end{array}$} & \multicolumn{4}{|c|}{$\begin{array}{l}\text { T2 } \\
\text { Midway program }\end{array}$} & \multicolumn{4}{|c|}{$\begin{array}{l}\text { T3 } \\
\text { End program }\end{array}$} & \multicolumn{4}{|c|}{$\begin{array}{l}\text { T4 } \\
\text { After program }\end{array}$} \\
\hline & $M$ & $S D$ & Max & Sum & $M$ & $S D$ & Max & Sum & $M$ & $S D$ & Max & Sum & $M$ & $S D$ & Max & Sum \\
\hline Number of ties & 4.25 & 2.14 & 9 & 68 & 6.38 & 4.32 & 20 & 102 & 7.31 & 5.29 & 22 & 117 & 6.38 & 5.32 & 22 & 102 \\
\hline New ties & & & & & 2.28 & 2.75 & 11 & 38 & 1.50 & 1.93 & 8 & 24 & 0.50 & 1.03 & 4 & 8 \\
\hline Lost ties & & & & & 0.19 & 0.40 & 1 & 3 & 0.56 & 1.03 & 4 & 9 & 1.44 & 2.06 & 8 & 23 \\
\hline Kept ties & & & & & 4.00 & 2.13 & 9 & 64 & 5.81 & 4.74 & 20 & 93 & 5.88 & 5.37 & 22 & 94 \\
\hline Ties on program ${ }^{a}$ & & & & & 5.13 & 4.36 & 18 & 82 & 6.56 & 4.95 & 20 & 105 & 5.31 & 4.50 & 18 & 85 \\
\hline
\end{tabular}

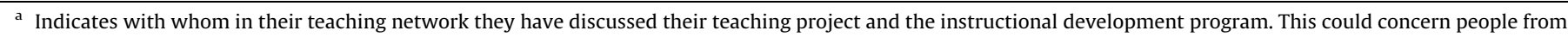
within as well as outside the program. 
Table 3

Descriptive statistics of participants' relations within and outside the instructional development program.

\begin{tabular}{|c|c|c|c|c|c|c|c|c|c|c|c|c|c|c|c|c|}
\hline & \multicolumn{4}{|c|}{$\begin{array}{l}\text { T1 } \\
\text { Before program }\end{array}$} & \multicolumn{4}{|c|}{$\begin{array}{l}\text { T2 } \\
\text { Midway program }\end{array}$} & \multicolumn{4}{|c|}{$\begin{array}{l}\text { T3 } \\
\text { End program }\end{array}$} & \multicolumn{4}{|c|}{$\begin{array}{l}\text { T4 } \\
\text { After program }\end{array}$} \\
\hline & $M$ & $S D$ & Max & Sum & $M$ & $S D$ & Max & Sum & $M$ & $S D$ & Max & Sum & $M$ & $S D$ & Max & Sum \\
\hline People within program & 0.31 & 0.48 & 1 & 5 & 1.25 & 1.57 & 5 & 20 & 1.69 & 1.74 & 5 & 27 & 1.50 & 1.71 & 5 & 24 \\
\hline People outside program & 3.94 & 1.95 & 8 & 63 & 5.25 & 3.30 & 16 & 84 & 5.63 & 4.30 & 17 & 90 & 5.06 & 3.99 & 17 & 81 \\
\hline Participants & 0.06 & 0.25 & 1 & 1 & 0.44 & 0.73 & 2 & 7 & 0.69 & 1.01 & 3 & 11 & 0.63 & 0.96 & 3 & 10 \\
\hline Central services & 0.06 & 0.25 & 1 & 1 & 0.31 & 0.48 & 1 & 5 & 0.44 & 0.63 & 2 & 7 & 0.38 & 0.62 & 2 & 6 \\
\hline Same department & 2.75 & 1.98 & 7 & 44 & 3.38 & 3.05 & 11 & 54 & 3.63 & 3.18 & 11 & 58 & 3.69 & 3.36 & 11 & 59 \\
\hline Different department & 0.44 & 1.13 & 4 & 7 & 1.62 & 2.65 & 9 & 26 & 2.63 & 3.23 & 10 & 42 & 1.81 & 2.60 & 9 & 29 \\
\hline Different university & 0.50 & 0.73 & 2 & 8 & 0.81 & 1.11 & 4 & 13 & 0.50 & 0.73 & 2 & 8 & 0.31 & 0.60 & 2 & 5 \\
\hline Other & 0.56 & 0.89 & 3 & 9 & 0.56 & 0.89 & 3 & 9 & 0.56 & 0.89 & 3 & 9 & 0.56 & 0.89 & 3 & 9 \\
\hline
\end{tabular}

Note. There is overlap between the different categories.

5.63 relations (i.e., with people not involved in the program). Participants mostly discussed their teaching over the course of the program with colleagues from their own department. Furthermore, some of the participants increasingly connected to people in educational central services and to people in the broader university (i.e., outside their department). The only group of people that remained constant in teachers' networks over the course of the program is the 'other' group, which concerned their partner, friends and family.

By only taking into account the number of ties at the different measurement moments, we cannot determine when e.g., a teacher has four people in his/her network at both T1 and T2, if he/she nominated the same four people, or completely changed his network by dropping the initial three from T1 and finding three new alters at T2 (Halgin \& Borgatti, 2012). To better capture change in ego-networks more specific measures are necessary. Therefore, to measure the dynamics of the networks over the course of the instructional development program, change and stability ratios (Cornelissen et al., 2014) were calculated (Table 4):

- stability ratio: (kept ties T2)/(number of ties T1);

- change ratio: (new ties $\mathrm{T} 2+$ lost ties $\mathrm{T} 2) /($ number of ties $\mathrm{T} 1+$ number of ties $\mathrm{T} 2$ ).

A stability ratio close to 1.00 indicates that the network remained stable, whereas a change ratio close to 1.00 shows that the network was dynamic. The standard deviation shows that there was much variation in participants' network change and stability, meaning that university teachers' networks evolved in various ways over the course of the instructional development program. Some networks remained stable (e.g., Joshua and Mary), whereas others clearly showed change (e.g., Tim and Isaac).

Mechanisms underlying change in university teachers' networks while participating in an instructional development program (RQ2)

To gain more insight into the possible mechanisms supporting or constraining network change in participants' networks, five indepth interviews with participants with different profiles of change (see Table 1 for selection) were analyzed (Fig. 6).

Coding of the qualitative data highlighted several mechanisms underlying network change over the course of the instructional development program. Table 5 provides an overview of supporting and constraining mechanisms underlying the formation, maintenance and loss of ties. Some teachers were intentional about whom they discussed their teaching practice with. They actively and purposefully sought people out, whereas other teachers indicated that most of their interactions happened by chance. A frequently recurring mechanism was departmental culture. The openness and willingness of colleagues in the department to talk about teaching varied steadily and was often described as having a significant supporting or constraining impact on network formation processes. Trust and friendship were identified as supporting mechanisms to maintain ties. It often concerned ties to people in the center of network maps. Another emerging theme was time. Teachers

Table 4

Network change and stability ratio's throughout the instructional development program.

\begin{tabular}{|c|c|c|c|c|c|c|c|}
\hline \multirow[t]{2}{*}{ ID } & \multirow[t]{2}{*}{ Name } & \multicolumn{2}{|l|}{$\mathrm{T} 1-\mathrm{T} 2$} & \multicolumn{2}{|l|}{ T2-T3 } & \multicolumn{2}{|l|}{ T3-T4 } \\
\hline & & Change ratio & Stability ratio & Change ratio & Stability ratio & Change ratio & Stability ratio \\
\hline 1 & John & 0.00 & 1.00 & 0.33 & 0.75 & 0.00 & 1.00 \\
\hline 2 & Theo & 0.33 & 0.75 & 0.00 & 1.00 & 0.00 & 1.00 \\
\hline 3 & Jude & 0.33 & 1.00 & 0.25 & 0.75 & 0.11 & 1.00 \\
\hline 4 & Joshua $^{a}$ & 0.09 & 1.00 & 0.00 & 1.00 & 0.00 & 1.00 \\
\hline 5 & Mary & 0.26 & 1.00 & 0.04 & 1.00 & 0.00 & 1.00 \\
\hline 6 & Eliah $^{\mathrm{a}}$ & 0.00 & 1.00 & 1.00 & 0.00 & 1.00 & 0.00 \\
\hline 7 & Tim & 0.25 & 0.75 & 0.20 & 1.00 & 0.17 & 0.83 \\
\hline 8 & Mat & 0.11 & 1.00 & 0.00 & 1.00 & 0.25 & 0.60 \\
\hline 9 & Phil & 0.11 & 1.00 & 0.20 & 0.80 & 0.11 & 0.80 \\
\hline 10 & Lucas & 0.20 & 1.00 & 0.14 & 1.00 & 0.41 & 0.63 \\
\hline 11 & Casper & 0.17 & 0.83 & 0.14 & 1.00 & 0.00 & 1.00 \\
\hline 12 & Isaac $^{\mathrm{a}}$ & 1.00 & 0.00 & 1.00 & 0.00 & 0.00 & 0.00 \\
\hline 13 & Sophie & 0.27 & 1.00 & 0.08 & 0.86 & 0.27 & 0.67 \\
\hline 14 & David & 0.38 & 0.80 & 0.11 & 1.00 & 0.11 & 0.80 \\
\hline 15 & Rose $^{a}$ & 0.00 & 1.00 & 0.44 & 1.00 & 0.47 & 0.38 \\
\hline 16 & Roxanne $^{a}$ & 0.38 & 1.00 & 0.05 & 1.00 & 0.00 & 1.00 \\
\hline$M$ & & 0.24 & 0.88 & 0.25 & 0.82 & 0.18 & 0.73 \\
\hline$S D$ & & 0.24 & 0.25 & 0.32 & 0.33 & 0.27 & 0.34 \\
\hline
\end{tabular}

a Teachers selected for interview. 


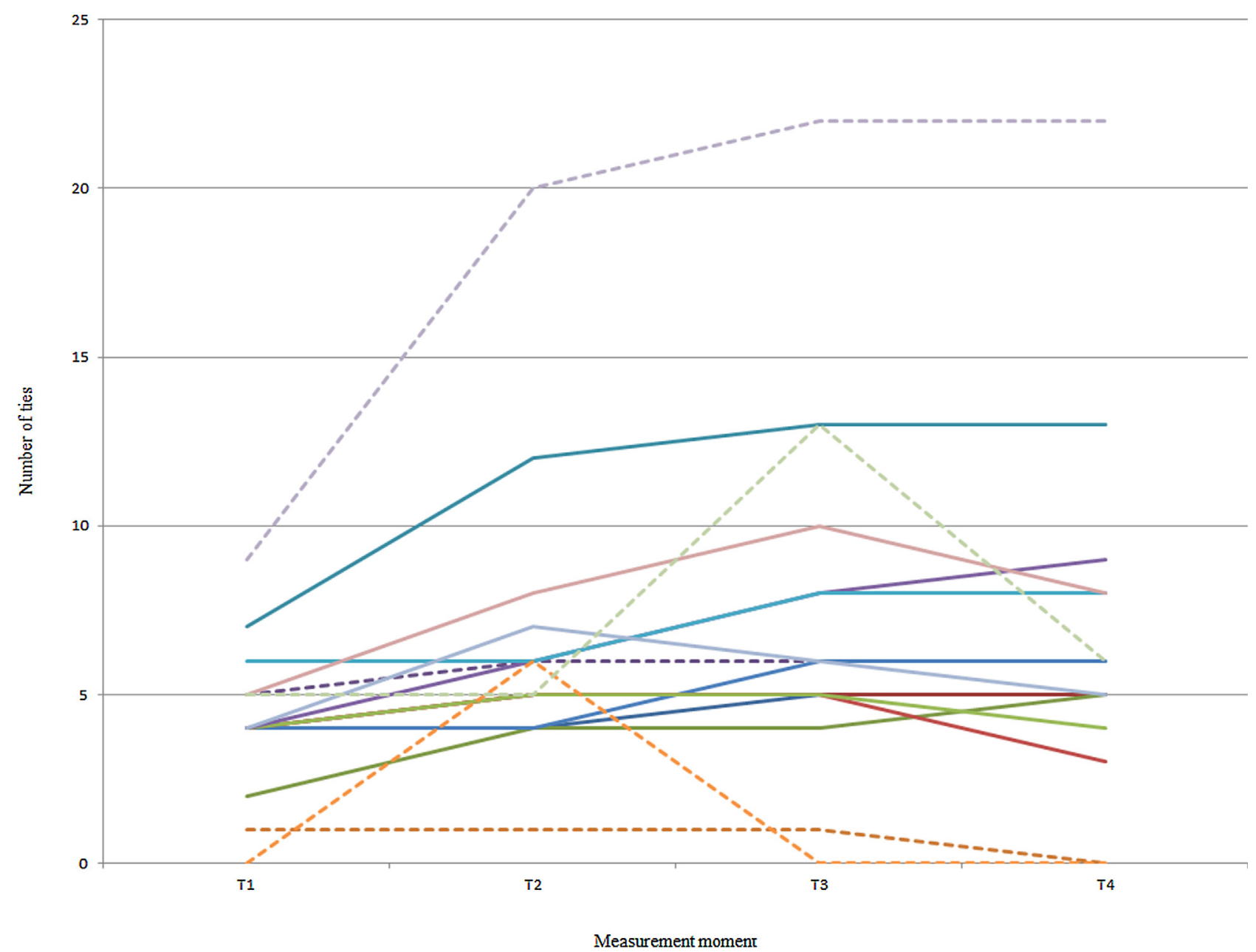

Fig. 6. Change in number of ties throughout the instructional development program. Note. The participants selected for interview are displayed in dotted lines.

indicated that they did not connect or got disconnected as a result of the time restrictions; emphasizing the balancing act teachers have to pull off in the light of the other dimensions that add complexity to their academic career, such as research, service and administrative activities. Furthermore, access and proximity (e.g., colleague next door, transition zones to meetings) also determined the presence or loss of ties during the instructional development program. Turnover of staff was also named as a reason for change in networks (e.g., new teaching assistants, retirement, maternity leave, new job opportunities or participation in educational boards). Hierarchy was indicated as having a negative influence on interaction because of power issues. Finally, the perceived (in)experience or (non)expertise of people was named as a mechanism supporting or constraining the formation of ties.

The value created through networks while participating in an instructional development program (RQ3)

To grasp the value of participants' networks as they participate in the instructional development program, the five in-depth interviews with participants with different profiles of change (see Table 1) were analyzed. All teachers reported value, except for the teacher with the isolated network profile. This participant indicated that $\mathrm{s} /$ he did not discuss his/her teaching project or the program, and did not feel the need to. Various types of value were identified as resulting from interactions on the teaching project or the instructional development program. Expressive value was reported regularly, for instance personal support such as venting about the hard work in light of the program, or affirmation instilling confidence about what one was developing for his/her project. Instrumental value (i.e., work-related) was also described, detailing for instance how exchanges with people in their network confronted their views on teaching and education, gave them ideas and feedback for their teaching practice, and evolved into jointly teaching a course. Moreover, interactions related to the program led to new contacts or increased 'know-who'. Participants indicated that - because of their newly acquired teaching expertise - they were now asked themselves for advice on teaching matters. Table 6 provides an overview of the value created through networks as reported by the interviewed participants.

\section{Conclusion and discussion}

This study examined the extent to which university teachers' social networks changed as they participated in an instructional development program, which mechanisms supported or constrained this network change, and the extent to which networks created value according to the teachers. A longitudinal social network approach was combined with follow-up in-depth interviews to uncover university teachers' collegial interactions over the course of an instructional development program. Most instructional development programs are directed at influencing individual teachers' learning and behavior (Stes et al., 2010). However, while teachers undertake instructional development as 
Table 5

Mechanisms supporting and constraining network change throughout the instructional development program.

\begin{tabular}{|c|c|c|}
\hline Mechanism & Supporting & Constraining \\
\hline Network intentionality & $\begin{array}{l}\text { 'Depending on what I want to know, I select who I talk to. (...) I } \\
\text { can always rely on the people in the inner circle [of the network } \\
\text { maps]. I think the people in the outer circle are new because of } \\
\text { the program. (...) The inner circle I'm already aware of and the }\end{array}$ & $\begin{array}{l}\text { 'Do I think about whom I talk to about my teaching practice...? I } \\
\text { don't know... (...) I think I tend to listen rather than actively } \\
\text { participate.' [\#12, isolated] }\end{array}$ \\
\hline
\end{tabular}

Departmental culture

Trust and friendship

Time

Access and physical proximity

Hierarchy

Experience and/or expertise outer circle are the people that raise my awareness.' [\#16, expansive network]

‘My position may not be very representative, I don't know, but I consider myself lucky to be working in a relatively open working environment where people talk very openly, without having the feeling of being checked. (...) I notice that colleagues are not ashamed about this and that is reassuring, like yes everyone makes mistakes. (...) They can admit their mistakes and that their teaching practice is still open to improvement.' [\#4, average stable network]

'If there was anything that I was insecure about, these were the two people I could always rely on, with whom I have a solid basis of trust, and with whom I talk a lot about education. They were very interested in some of the things I learned in the program, the tips and tricks that were taught there.' [\#4, average stable network]

'Those [in the middle of the network maps] are also the people that I have more of a friendship bond with. And I do think that's important.' [\#16, expansive network]

'Yes, I would spend more time talking about education. Of course, it would have to be in a structured way. If you spend time on it, you have to get something out of it. That may be a selfish way to look at it but...' [\#6, small stable network] 'The new people are there [on the network maps] because of the program. There's also someone new [on the network map] and he's from the same department but he wasn't in the same meeting group, but it's also because of the program that we started talking.' [\#15, flexible network]

'Well, maybe because a vacuum was created here [on the network map], and the person responsible for the educational quality in the department had left, I've discussed some of the parts of the teaching project with [person $\mathrm{xx}$ ] as coordinator of the educational quality.' [\#6, small stable network]

"At that time [person $\mathrm{xx}$ ] was also the chair of education so regarding the administrative and practical side of [topic $\mathrm{xx}$ ] in my teaching project, [person $\mathrm{xx}$ ] often knew the details. So it was easy to walk by the office and ask [person $\mathrm{xx}$ ]: 'How does this all work?' [\#4, average stable network]

'In the meanwhile I've been talking to [participant $\mathrm{xx}$ from the same department]. [Participant $\mathrm{xx}$ ] is also someone who I didn't know was a good teacher. He teaches a totally different subject. And it's the way that [participant $\mathrm{xx}$ ] teaches that I've also learned from.' [\#16, expansive network]
'It's important [to talk about teaching] because we all have to be on the same page but that's not going so well, I have to admit. (...) I would like to talk more about my teaching practice but there also has to be a certain positive attitude. Most of them [people on the network maps] have kind of their own opinion and it's very difficult to change their minds.' [\#12, isolated network]

'I think we need more time [for teaching and talking about it]. Time is the most important factor. Now it has to happen too often in between other things.' [\#12, isolated network]

'I've got the idea that people work more from home, and that's why there're less people at the office. If you could just knock on people's door. But it has to be informal. You cannot send an email saying I would like to talk to you about this. That would come across unnaturally.' [\#15, flexible network]

'It's just about power. They [the chairs] don't necessarily do it better or good. There's just nobody who contradicts them. My colleagues dare to contradict me. I think the higher up they are, the more isolated they become, and then they start to show some dictatorial traits. It has two sides, you know.' [\#12, isolated network]

'No, I don't like to be someone who people come to with questions or advice about their own teaching practice. I think that's okay. But, of course, I think they will only come if you are more experienced so I won't be the first person they come to.' [\#15, flexible network] individuals, the social side of instructional development programs should also be considered (e.g., Gale, 2011; Postareff et al., 2007). While it is often assumed that participants connect to other people, few studies have actually explored participants' interactions before, during and after instructional development programs. We will now discuss four key themes that emerged from these study's findings, and may yield suggestions for practice and research.

In general university teachers expanded their networks over the course of the instructional development program, and different profiles of network change were discerned

Our findings demonstrated that participants had different trajectories of network change over the course of the instructional development program. Some teachers stayed relatively isolated over the course of the program, whereas others expanded their networks or kept stable networks. Despite the extent to which the networks differed at the start of the program and how different they changed over the course of the program, what was constant is that at T4 (after the program) teachers' networks stabilized in line with T3. This suggests that the program had a lasting influence on the participants' network (at least short-term, 6 months after the program). Moreover, the largest growth in the network occurred between $\mathrm{T} 1$ and $\mathrm{T} 2$. This may prove a crucial point in programs to make teachers aware of their network and its possibilities for their teaching practice. Raising teachers' awareness about networks and the potential benefits of actively shaping them (Burt \& Ronchi, 2007; de Laat \& Schreurs, 2013) can become part of an instructional development program, with the aim to further augment the effects of organized instructional development activities. As our findings demonstrated that teachers' networks changed the most between T1 (before the program) and T2 (midway the program), the beginning of the program might be the most suitable moment for such an intervention. Studies in the field of learning and professional development have suggested that enhanced social networks should be regarded as an outcome of training programs (Van den Bossche \& Segers, 2013) to support the transfer of what is learned during the program back to the department. Visualizing 
Table 6

Perceived expressive and instrumental value of networks in view of the instructional development program.

Expressive value

Soundboarding or venting

'This concerned, yes, questions like 'how are you?' 'is it [the instructional development program] not too heavy?' Because it's all part of it. 'How do you go about the project?' 'What do they ask?'. So it's sincere interest on whether it's still feasible next to my other activities. They were also a soundboard when I was nagging or complaining a little bit too much (laughs).' [\#4, average stable network]

Feeling affirmed 'For instance, when [a colleague from the same department] uses a presentation, it always starts with 'what are we going to do today?'. Then summing up each point short and to the point. This is something very concrete that I've been doing as well from the start, and I know it works. And then, as you're following the program, this is often indicated by others as a good tip. So you know from your own experience and because others' are doing it as well that it's a good way to start a class.' [\#4, average stable network]

Instrumental value

Discovering shared teaching interests

Sharing experiences

Getting ideas or feedback

Applying ideas or feedback

Confronting or broadening one's vision on teaching

Learning to talk about teaching (pedagogical discourse)

Deciding to teach a course together

Gaining 'know-who' (insight in others' teaching expertise)

Heightening efficiency

Being asked for feedback (raised perception of expertise)
'Because of the peer observation we did together [observing each other's classes, with another participant from the same department] and the interaction that came with it, we kind of discovered shared research and teaching interests.' [\#15, flexible network]

'They had also followed the program the year before, and they told me what they had done. For instance, one of them had been working on a syllabus, and the other one had done something on assessment. So we talked about how we dealt with the program.' [\#15, flexible network]

'We also had, and I liked that, small group sessions to discuss our projects. There was someone from another department who was organizing an assessment for students on the online learning environment. I thought it was very nice that we shared these ideas, and I think that things like these are instructive.' [\#6, small stable network]

'Like when you get feedback on your class, and afterwards you talk about the topic of the class and possible bottlenecks. Sometimes we also talked about the evaluation and how to interact with big groups of students. You could use all this for your own students and, yes, apply it in your teaching.' [\#15, flexible network] 'In that sense, the tutor opened a kind of new door. Something that I hadn't thought about before, such as that pedagogical literature, scientific reflection on the practice of teaching. That's certainly something that these other people [points on network map] hadn't brought along. So in that way, she did broaden my view on education.' [\#4, average stable network]

'I think that education can be different, or that's what I've learned during the program. There were people from the Science department, someone from the Law department but you feel that the types of education aren't necessarily the same and that it wouldn't be ideal if it were the same in these different environments and that you have to adapt to the context.' [\#6, small stable network]

'The emphasis was sometimes also placed on being able to reason about your teaching practices, so being able to talk about education and to adopt a kind of pedagogical discourse. I reckon this important, especially if you have to report to the university authorities such as describe your teaching practice or draw up a self-evaluation report.' [\#4, average stable network]

'Because of the peer observation we did together [with another participant from the same department] and the interaction that came with it, we kind of discovered shared research and teaching interests. One of the consequences was that we started teaching a course together.' [\#15, flexible network]

'Yes, sometimes you simply don't know that something or someone exists. Like when I was working on the assessment policy for my project, I didn't know that there was someone within the department just for that (...). $\mathrm{Xx}$ appeared to be a super valuable person because she really understood what I couldn't explain within the small group session because it's typical for our field.' [\#16, expansive network]

'My project would have looked much thinner if these people [on the network map] wouldn't have been there. Yes, I might have achieved the same outcome but probably much slower.' [\#16, expansive network] 'They were also very interested in some of the things that I came back with from the program, or in the tips and tricks that are given, for instance, concerning the evaluations and reports that are becoming increasingly important. So that I could give that input.' [\#4, average stable network] teachers' networks at the start of the program may enhance awareness about their networks, and provide insight into possible relational barriers prior to training (Hatala \& Fleming, 2007).

\section{University teachers' connections to people outside the instructional development program grew substantially, however they limitedly connected to other participants}

Over the course of the instructional development program, participants connected both to other participants and to people outside the program. Teachers heavily relied on their network outside the instructional development program, which resembles findings by Rienties and Kinchin (2014). Most of the participants' external connections were to colleagues in their own department, but also relations with colleagues from different departments or universities, friends and family proved substantial. Crawford (2010) indicated that 'externality' is significant in shaping professional development. When participants go back to their workplace after training, a substantial network has shown to enhance the transfer of what has been learned in the training program (Hatala \& Fleming, 2007; Van den Bossche \& Segers, 2013).
The overall network between participants started off fragmented and gradually grew closer as the program evolved. However, large distances between several participants remained, implying that teaching resources did not spread easily among the program participants. Three participants remained (relatively) isolated over the course of the program, which resembles findings by Moses et al. (2009). Eleven teachers indicated that they did not discuss their teaching practice with other participants during the program. It is remarkable that participants indicated few relations with coparticipants, since they provided feedback to each other as part of a 'critical friend' system, and observed each other during teaching. The instructional development program in this study did not explicitly aim to change teachers' networks, and the teaching project was an individual endeavor aimed at their teaching practice at the workplace. Whereas, if the program would have collective tasks or goals, connections between participants may have been stronger (Rienties \& Kinchin, 2014). Another explanation may be that participants may have forgotten these interactions with coparticipants due to the open question format (Wright \& Pescosolido, 2002). However, it may just be as likely that respondents did not recognize these feedback moments as valuable discussions, or that 
these incidental discussions did not contribute to their interpretation of a network tie around teaching. As earlier research showed that a relationship (e.g., friendship) may not mean the same to everybody (Lima, 2001), our work implies the need to explicitly study variation in the interpretation of social network questions, thereby contributing to issues of reliability in network research.

Exchanging experiences and resources with other participants during instructional development programs has been shown helpful and beneficial for further collegial interactions after the program (e.g., Skeff et al., 1998). Academic developers could be proactive in helping scholars in isolated environments (Moses et al., 2009). This may encourage the exchange of resources between participants and stimulate networks among the participants (Jippes et al., 2013). Programs are often very individual-focused, rather encouraging to read a book or an article than referring to experts or peers with similar experiences. Teachers' experiences may benefit from a more groupbased approach to instructional development programs, e.g., by a more explicit collaborative design (using peer feedback, critical friends, formative intergroup exchanges, brainstorm sessions, etc.), support of tutors who may facilitate intra- and intergroup exchanges, or by making participants' existing teaching expertise explicit to stimulate meaningful exchanges (Baker-Doyle \& Yoon, 2010).

Several mechanisms supported and constrained university teachers' network change over the course of the instructional development program

Qualitative analyses uncovered several mechanisms that may underlie network change over the course of instructional development programs. Trust and friendship proved important mechanisms supporting networks over the course of instructional development. As trust and friendship relations have been suggested to be relatively stable (Shah, 2000), these may be important mechanisms for maintaining ties during a training program (Levin \& Cross, 2004). Our study showed that participants differed considerably in the extent to which they were intentional about shaping their network. A way to stimulate teachers to craft their networks in ways that support teaching, is that organizations (such as universities), may put in place structures and practices that both support and encourage teachers to reach out to colleagues, which may also influence individuals' intentions and perceptions of the climate in which they work (Moolenaar et al., 2014).

While this study focused on social relations that would be supportive of teachers' development, our qualitative analyses also revealed mechanisms that constrained network change over the course of an instructional development program. Findings showed that limited time for teaching, difficult access to people, distance between people (physical proximity), and strict hierarchical relations may act as constraining network mechanisms. Furthermore, teachers' departmental culture appeared a crucial mechanism underlying network change when participating in an instructional development program. If teachers go back to their department after the program has finished and what they have learned does not match with the departmental culture, the uptake of the program may be at risk. Aligning the program with the teaching and learning regimes of the department to which participants return (Mathieson, 2011; Trowler \& Cooper, 2002) may be facilitated by involving people from the department in the program (Baker, Reeves, Egan-Lee, Leslie, \& Silver, 2010), or by encouraging participants to observe experienced (expert) teachers from their own department and vice versa. Participants can be exposed to key individuals in teaching and education (Moses et al.,
2009) within their department or in the broader institution, e.g., relationships can be brokered with people in educational central services.

Expressive and instrumental value were created through networks while participating in an instructional development program

A qualitative exploration of the extent to which value is created through networks, showed that teachers reported both expressive or affective value (e.g., venting, feeling affirmed) and instrumental or work-related value (e.g., getting ideas or feedback, confronting one's vision on teaching). All teachers but one indicated that value was created through their networks. As such our exploration suggests the potential value or benefits of interactions about teaching as they participate in an instructional development program.

\section{Delimiters and further research}

Some delimiters can be offered that constrain the generalizability of our study. In order to further explore the impact of networks for instructional development, future studies may opt to include a control group of teachers who do not take part in an instructional development program to benchmark the network growth against. Teachers may experience similar network change as their careers develop, even if they did not participate in instructional development.

This study focused on the presence and change of ties. However, collegial interactions about teaching do not automatically contribute to improved instructional development. More is required than sharing information to ensure that teachers actually develop further. Qualitative network research suggested that the quality and depth of interactions may be key to providing teachers opportunities to learn in interactions (Coburn \& Russell, 2008). Further research into how different types of value are created as well as into the content and quality of relationships for instructional development is needed. Future studies may simultaneously consider the effects of instructional development programs on teachers' individual learning and behavior, and their social networks. In addition, they may consider the potentially different needs of teachers in different stages of development (Van Waes et al., 2015). K-12 research suggested that teachers have different support needs, depending on their level of implementation of an innovation at the start of an instructional development program. At the lowest level of implementation, teachers needed to be exposed to instructional development focused on student learning; at the intermediate level they needed opportunities to experiment and explore; and at the high initial implementation level collegial interactions proved most helpful (Frank, Zhao, Penuel, Ellefson, \& Porter, 2011). Further examination of how social networks can potentially support teachers' instructional development within these stages is timely.

This study offers a unique contribution by using a social network approach to understand the extent to which university teachers' collegial interactions changed over the course of an instructional development program, which mechanisms underlay these changes, and which value was created. We combined longitudinal social network methods with in-depth qualitative data, acquired through a novel and extensive approach to examine teachers' networks. By focusing on the social networks that may support individual university teachers in improving their teaching, we take the first steps to simultaneously study the individual and social side of instructional development. 
Appendix A.

Examples of (anonymized) network maps throughout the instructional development program (T1-T4) of one participant as basis for the interviews

Note. Four sheets of A3-sized paper with three concentric circles were placed on the table to visualize the respondent's ego-network
(Hogan et al., 2007; adapted by Van Waes et al., 2015) throughout the instructional development program (T1-T4). The network maps were constructed based on the participant's network questionnaires. The circles on the maps indicate the degree of closeness with the contact. Based on these network maps, questions were asked to gain insight into the mechanisms underlying network change throughout the instructional development program (Figs. A.1-A.4).

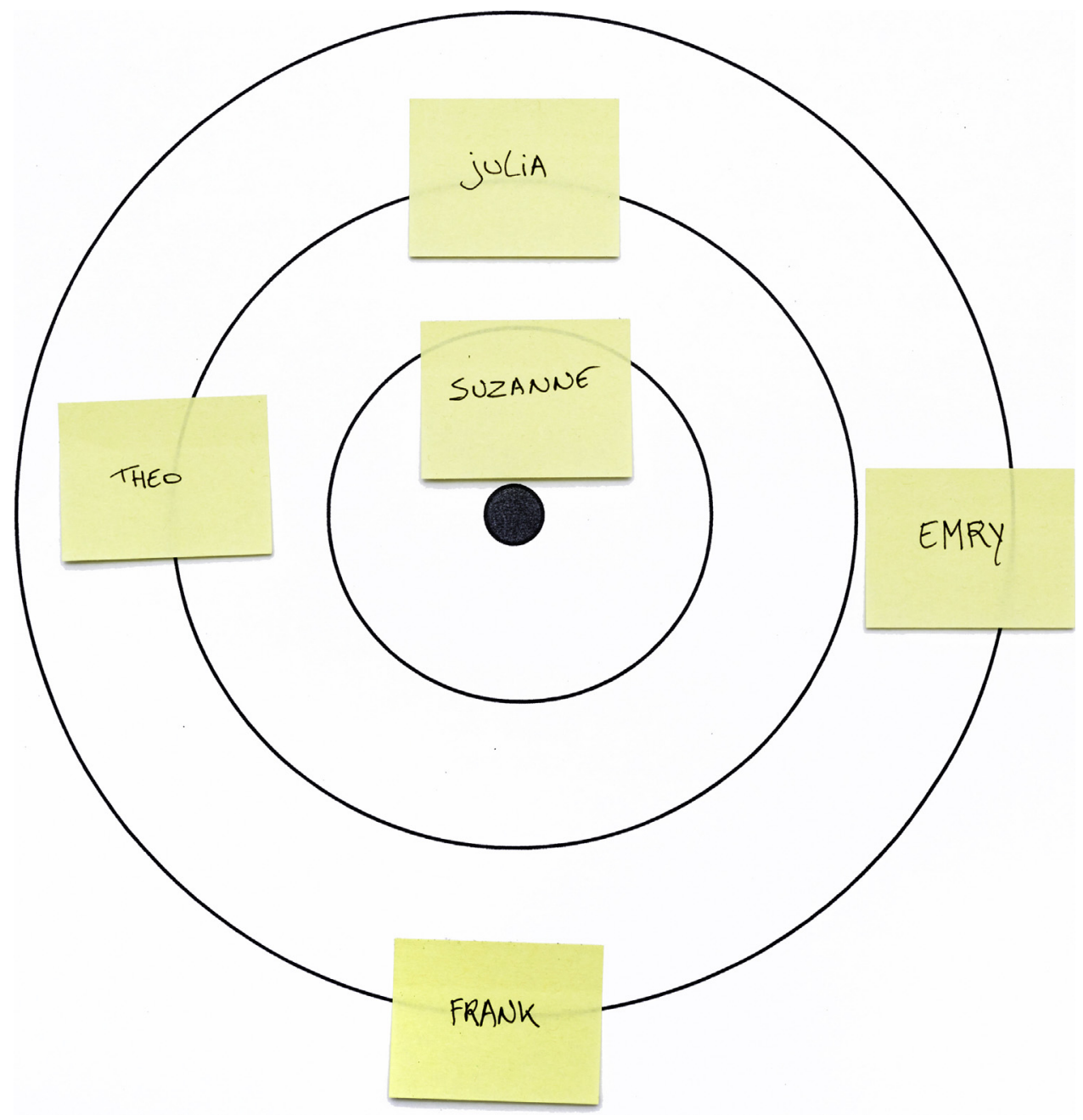

Fig. A.1. Example of network map at T1. 


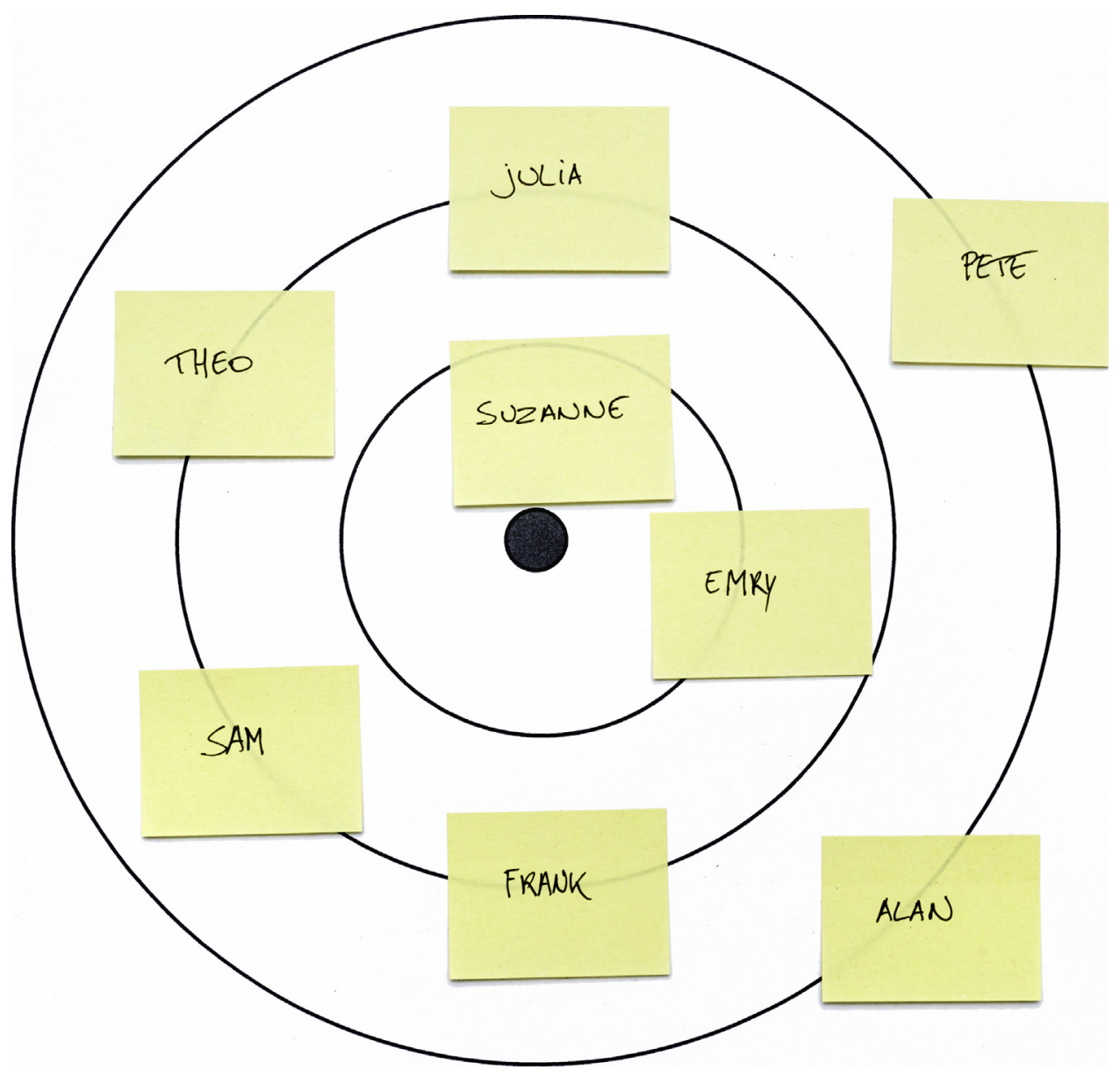

Fig. A.2. Example of network map at T2. 
G Model

JSEE-553; No. of Pages 18

ARTICLE IN PRESS

S. Van Wees et al./Studies in Educational Evaluation $x x x$ (2015) $x x x-x x x$

15

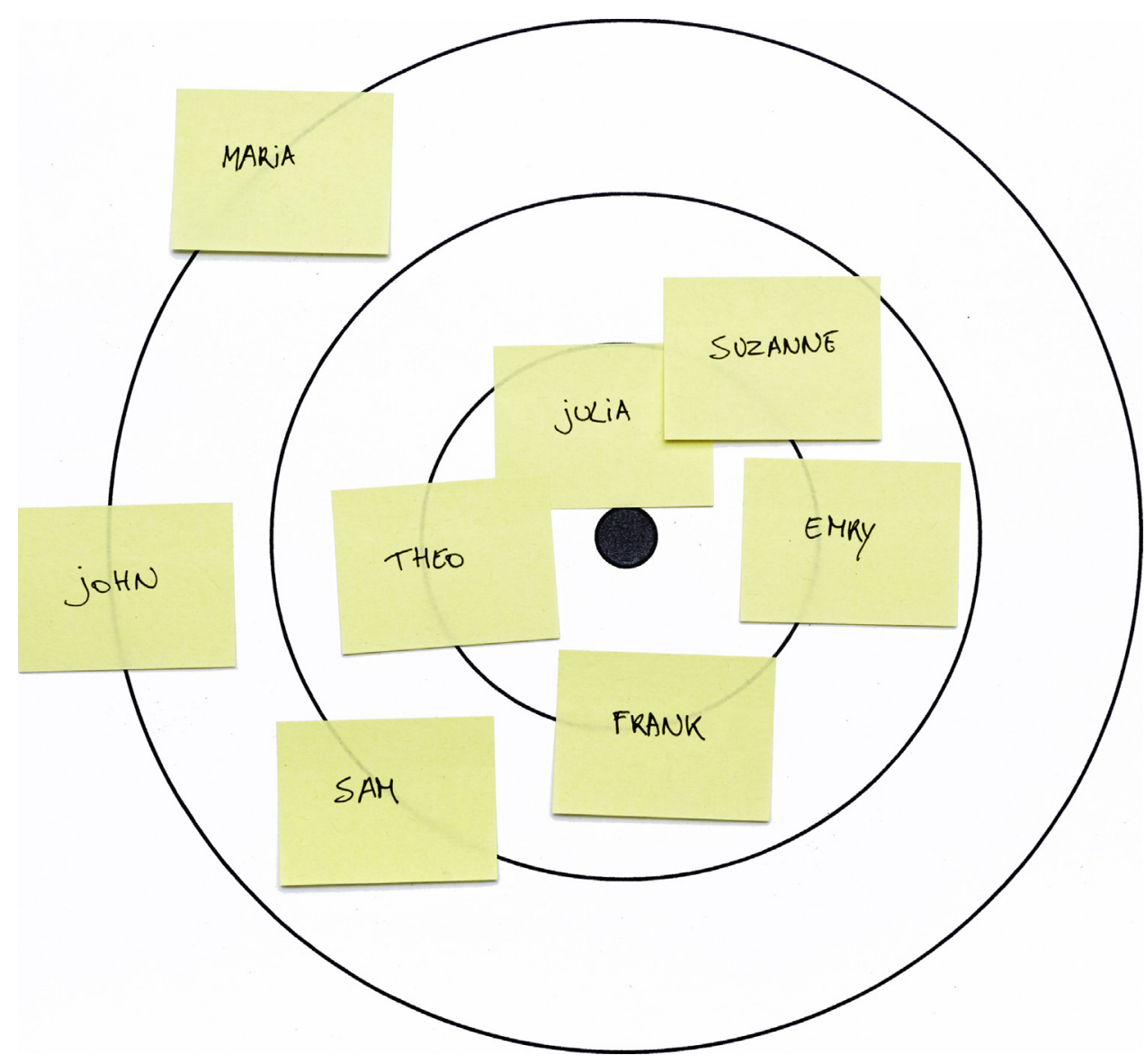

Fig. A.3. Example of network map at T3.

Please cite this article in press as: S. Van Wees, et al.. Uncovering changes in university teachers' professional networks during an instructional development program. Studies in Educational Evaluation (2015), http://dx.doi.org/10.1016/j.stueduc.2015.02.003 


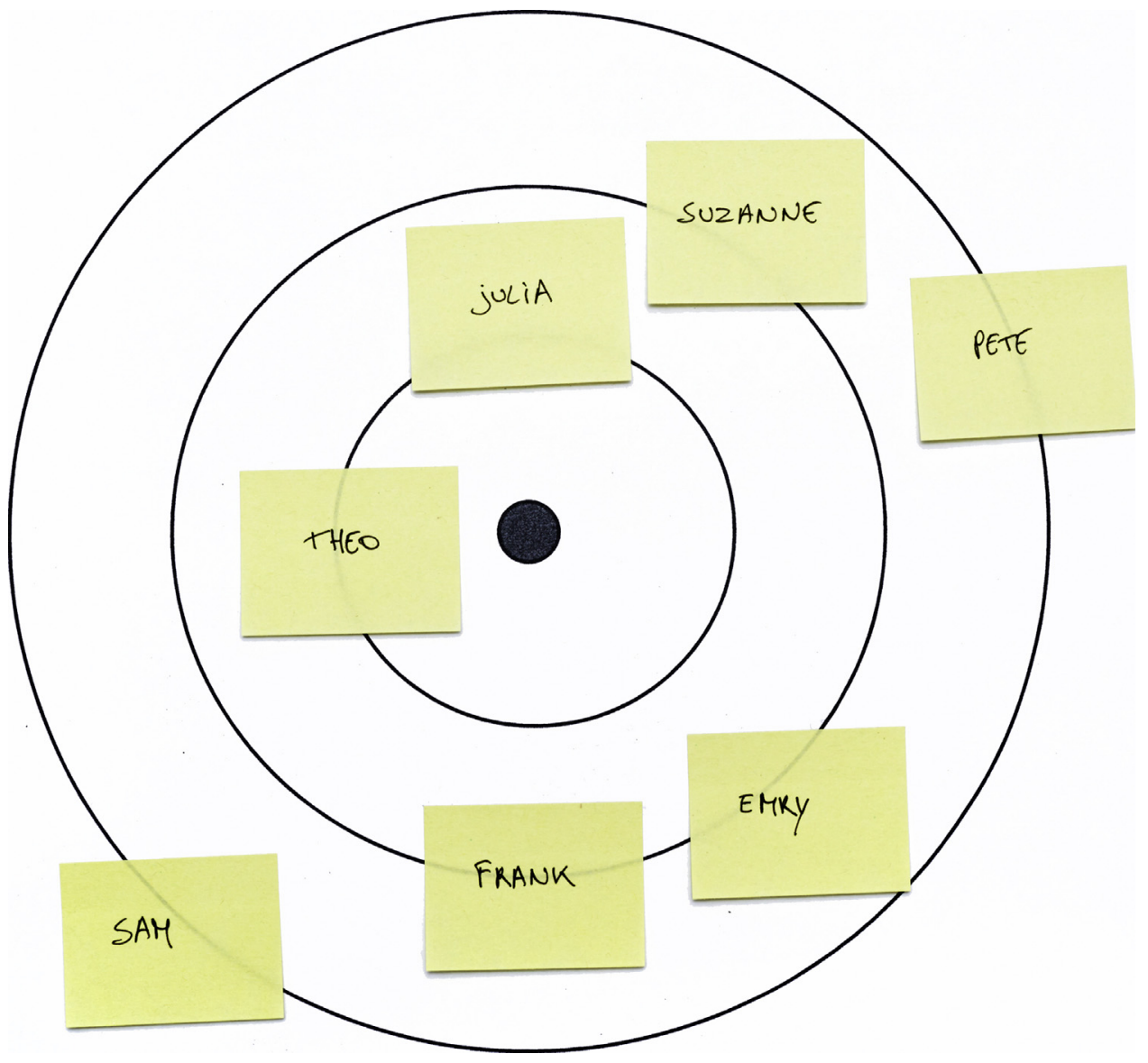

Fig. A.4. Example of network map at T4.

\section{Appendix B \\ Structure of interview guide}

Introductory script

Warm-up

Mechanisms underlying network change when following an instructional development program (RQ2)

Network change

- New ties

- Lost ties

- Kept ties

Network intentionality (based on Moolenaar

et al., 2014)

- Actively seeking relations

- Belief in having the right relations

- Assessing relations

- Linking to connect

Departmental culture with about your teaching practice program? person add for your teaching?
Based on the four questionnaires that you filled out throughout the instructional development program [network questionnaires T1-T4], we constructed these four pictures [network maps] of the people that you have been communicating

- What do you think of these pictures? What strikes you?

- Have you ever thought about your teaching practice in this way?

- Why did you start/stop/keep talking with [person xx on the network map] throughout the instructional development

- To what extent is [person $\mathrm{xx}$ ] important for your teaching/is this person not important anymore? What does/did this

- To what extent do you think that talking about your teaching is important or useful?

- Do you actively search out new relations with people who can help you with your teaching?

- Do you believe that having the right set of relations will improve your teaching?

- Do you sometimes assess the teaching relations that you have?

- Do you like to be a source of advice and counsel on teaching for others?

- To what extent do colleagues in your department talk openly about teaching?

- Is talking about teaching encouraged in any way?

- When and where can people in your department talk about teaching?

- Would you like to interact more with your colleagues about teaching?

- What prevents more interaction about teaching? What could make it easier to talk about teaching?

Value created through networks when following an instructional development program (RQ3)

Value

In the questionnaires you indicated that you have talked with [person(s) $\mathrm{xx}$ ] about the instructional development program:

- What did you talk about with each of these persons?

- Did these talks help you in any way with your teaching project?

- To what extent would your teaching project have looked differently if these people on the maps had not been there?

- To what extent would you have liked to have less or more interaction about the program? Why?

Please cite this article in press as: S. Van Waes, et al.. Uncovering changes in university teachers' professional networks during an instructional development program. Studies in Educational Evaluation (2015), http://dx.doi.org/10.1016/j.stueduc.2015.02.003 


\section{References}

Anderson, C., \& McCune, V. (2013). Fostering meaning: Fostering community. Higher Education, 66(3), 283-296. http://dx.doi.org/10.1007/s10734-012-9604-6

Baker, L., Reeves, S., Egan-Lee, E., Leslie, K., \& Silver, I. (2010). The ties that bind: A network approach to creating a programme in faculty development. Medical Education, 44(2), 132-139. http://dx.doi.org/10.1111/j.1365-2923.2009.03549.x

Baker, P., \& Zeyferrell, M. (1984). Local and cosmopolitan orientations of faculty: Implications for teaching. Teaching Sociology, 12(1), 82-106.

Baker-Doyle, K. J., \& Yoon, S. A. (2010). Making expertise transparent: Using technology to strengthen social networks in teacher professional development. In A. Daly (Ed.), Social network theory and educational change (pp. 115-126). Cambridge, MA: Harvard Education Press.

Barnes, L. B., Agago, M., \& Coombs, W. (1998). Effects of job-related stress on faculty intention to leave academia. Research in Higher Education, 39(4), 457-469. http:/ dx.doi.org/10.1023/A:1018741404199

Baume, D. (2006). Towards the end of the last non-professions? International Journal for Academic Development, 11(1), 57-60. http://dx.doi.org/10.1080/13601440600579050

Boice, R. (1992). The new faculty member: Supporting and fostering professional development. San Francisco, CA: Jossey-Bass.

Borgatti, S. P., Everett, M. G., \& Freeman, L. C. (2002). Ucinet for windows: Software for social network analysis. Harvard: Analytic Technologies Retrieved from http:/ www.analytictech.com/downloaduc6.htm

Burt, R. S., \& Ronchi, D. (2007). Teaching executives to see social capital: Results from a field experiment. Social Science Research, 36(3), 1156-1183. http://dx.doi.org 10.1016/j.ssresearch.2006.09.005

Carolan, B. V. (2014). Social network analysis and educational research: Theory, methods, and applications. Thousand Oaks, CA: SAGE Publications.

Carrington, P. J., Scott, J., \& Wasserman, S. (2005). Models and methods in social network analysis. New York: Cambridge University Press.

Centra, J. A. (1989). Faculty evaluation and faculty development in higher education. In J. C. Smart (Ed.), Higher education: Handbook of theory and research (pp. 155-179). New York: Agathon Press.

Coburn, C., \& Russell, J. L. (2008). District policy and teachers' social networks. Education Evaluation and Policy Analysis, 30(3), 203-235.

Coburn, C., Russell, J. L., Kaufman, J. H., \& Stein, M. K. (2012). Supporting sustainability: Teachers' advice networks and ambitious instructional reform. American Journal of Education, 119(1), 137-182.

Cohen, A., Klein, K., Daly, A. J., \& Finnigan, K. (2011). Out with the old, in with the new: When are leader successions successful, new directions in leadership annual meeting. The Wharton School of Business University of Pennsylvania.

Cornelissen, F., Daly, A. J., Liou, Y., Chillier, S., Riordan, R., Wilson, K., et al. (2014) Network building in the master's program: The social dimension of developing teacher leader-researcher identity. Paper presented at the ECER.

Cox, M. D. (2004). Introduction to faculty learning communities. New Directions for Teaching and Learning, 97, 5-23. http://dx.doi.org/10.1002/tl.129

Crawford, K. (2010). Influences on academics' approaches to development: Voices from below. International Journal for Academic Development, 15(3), 189-202. http:/ dx.doi.org/10.1080/1360144x.2010.497669

Daly, A. J. (Ed.). (2010). Social network theory and educational change. Cambridge, MA: Harvard Education Press.

de Laat, M., \& Schreurs, B. (2013). Visualizing informal professional development networks: Building a case for learning analytics in the workplace. American Behaviora Scientist, 57(10), 1421-1438. http://dx.doi.org/10.1177/0002764213479364

Denicolo, P., \& Becker, L. (2013). Teaching in higher education. London: SAGE Publications, Limited.

Devlin, M., \& Samarawickrema, G. (2010). The criteria of effective teaching in a changing higher education context. Higher Education Research E Development 29(2), 111-124. http://dx.doi.org/10.1080/07294360903244398

Everett, M., \& Borgatti, S. P. (2014). Networks containing negative ties. Social Networks, 38, 111-120.

Feld, S. L., Suitor, J. J., \& Gartner Hoegh, J. (2007). Describing changes in personal networks over time. Field Methods, 19(2), 218-236.

Fidler, P., Neururer-Rotholz, J., \& Richardson, S. (1999). Teaching the freshman seminar: Its effectiveness in promoting faculty development. Journal of the First-Year Experience \& Students in Transition, 11(2), 59-73.

Fouche, I. (2006). A multi-island situation without the ocean: Tutors' perceptions about working in isolation from colleagues. International Review of Research in Open and Distance Learning, 7(2).

Frank, K. A., Zhao, Y., Penuel, W. R., Ellefson, N., \& Porter, S. (2011). Focus, fiddle, and friends: Experiences that transform knowledge for the implementation of innovations. Sociology of Education, 84(2), 137-156. http://dx.doi.org/10.1177/ 0038040711401812

Fuhse, J., \& Mützel, S. (2011). Tackling connections, structure, and meaning in networks: Quantitative and qualitative methods in sociological network research. Quality \& Quantity, 45(5), 1067-1089. http://dx.doi.org/10.1007/s11135-0119492-3

Furco, A., \& Moely, B. E. (2012). Using learning communities to build faculty support for pedagogical innovation: A multi-campus study. Journal of Higher Education, 83(1), $128-153$.

Gale, H. (2011). The reluctant academic: Early-career academics in a teaching-orientated university. International Journal for Academic Development, 16(3), 215-227. http://dx.doi.org/10.1080/1360144X.2011.596705

Gallucci, C. (2008). Districtwide instructional reform: Using sociocultural theory to link professional learning to organizational support. American Journal of Education, 114(4), 541-581. http://dx.doi.org/10.1086/589314
Gizir, S., \& Simsek, H. (2005). Communication in an academic context. Higher Education, 50(2), 197-221. http://dx.doi.org/10.1007/s10734-004-6349-x

Halgin, D. S., \& Borgatti, S. P. (2012). An introduction to personal network analysis and tie churn statistics using E-NET. Connections, 32(1), 37-48

Harnish, D., \& Wild, L. A. (1993). Peer mentoring in higher education: A professional development strategy for faculty. Community College Journal of Research and Practice, 17(3), 271-282. http://dx.doi.org/10.1080/0361697930170307

Hatala, J.-P. (2006). Social network analysis in human research development: A new methodology. Human Resource Development Review, 5(1).

Hatala, J.-P., \& Fleming, P. R. (2007). Making transfer climate visible: Utilizing social network analysis to facilitate transfer of training. Human Resource Development Review, 6(1), 33-63.

Hicks, M., Smigiel, H., Wilson, G., \& Luzeckyj, A. (2010). Preparing academics to teach in higher education: Final report. Sydney: Australian Learning and Teaching Council.

Hogan, B., Carrasco, J. A., \& Wellman, B. (2007). Visualizing personal networks: Working with participant-aided sociograms. Field Methods, 19(2), 116-144.

Howland, J., \& Wedman, J. (2004). A process model for faculty development: Individualizing technology learning. Journal of Technology and Teacher Education, 12(2), 239-262.

Hubball, H., Collins, J., \& Pratt, D. (2005). Enhancing reflective teaching practices: Implications for faculty development programs. Canadian Journal of Higher Education, 35(3), 57-81.

Ibarra, H. (1993). Personal networks of women and minorities in management: A conceptual framework. Academy of Management Review, 18(1), 56-87.

Ibarra, H. (1995). Race, opportunity, and diversity of social circles in managerial networks. Academy of Management Journal, 38(3), 673-703.

Jippes, E., Steinert, Y., Pols, J., Achterkamp, M. C., van Engelen, J. M. L., \& Brand, P. L. P. (2013). How do social networks and faculty development courses affect clinical supervisors' adoption of a medical education innovation? An exploratory study. Academic Medicine, 88(3), 398-404. http://dx.doi.org/10.1097/ ACM.0b013e318280d9db

Johnsrud, L. K., \& Heck, R. (1998). Faculty worklife: Establishing benchmarks across groups. Research in Higher Education, 39(5), 539-555. http://dx.doi.org/10.1023/ A:1018749606017

Kilduff, M., \& Tsai, W. (2003). Social networks and organizations. London, UK: Sage.

Labianca, G. (2014). Negative ties in organizational networks. In D. J. Brass, G. Labianca, A. Mehra, D. S. Halgin, \& S. P. Borgatti (Eds.), Contemporary perspectives on organizational social networks (pp. 239-259). Emerald Group Publishing Limited.

Levin, D. Z., \& Cross, R. (2004). The strength of weak ties you can trust: The mediating role of trust in effective knowledge transfer. Management Science, 50(11), 14771490.

Lima, J. (2001). Forgetting about friendship: Using conflict in teacher communities as a catalyst for school change. Journal of Educational Change, 2(2), 97-122. http:// dx.doi.org/10.1023/a:1017509325276

Little, J. W. (1990). The persistence of privacy: Autonomy and initiative in teachers' professional relations. Teachers College Record, 9(4), 509-536.

Lockwood, F., \& Latchem, C. (2004). Staff development needs and provision in commonwealth countries: Findings from a commonwealth of learning training impact study. Distance Education, 25(2), 159-173. http://dx.doi.org/10.1080/0158791042000262102

Mathieson, S. (2011). Developing academic agency through critical reflection: A sociocultural approach to academic induction programmes. International Journal for Academic Development, 16(3), 243-256. http://dx.doi.org/10.1080/1360144x.2011.596730

McDonough, K. I. M. (2006). Action research and the professional development of graduate teaching assistants. Modern Language Journal, 90(1), 33-47. http:// dx.doi.org/10.1111/j.1540-4781.2006.00383.x

Moolenaar, N. M. (2012). A social network perspective on teacher collaboration in schools: Theory, methodology, and applications. American Journal of Education, 119(1), 7-39. http://dx.doi.org/10.1086/667715

Moolenaar, N. M., Daly, A., Cornelissen, F., Liou, Y., Caillier, S., Riordan, R., Wilson, K., \& Cohen, N. A. (2014). Linked to innovation: Shaping an innovative climate through network intentionality and educators' social network position. Journal of Educational Change, 15(2), 99-123. http://dx.doi.org/10.1007/s10833-014-9230-4

Moses, A. S., Skinner, D. H., Hicks, E., \& O'Sullivan, P. (2009). Developing an educator network: The effect of a teaching scholars program in the health professions on networking and productivity. Teaching and Learning in Medicine, 21(3), 175-179.

Palmer, P. J. (1999). Good talk about good teaching: Improving teaching through conversation and community. http://www.couragerenewal.org/parker/writings/good-talk/

Pataraia, N., Margaryan, A., Falconer, I., \& Littlejohn, A. (2013). How and what do academics learn through their personal networks. Journal of Further and Higher Education, 1-22. http://dx.doi.org/10.1080/0309877x.2013.831041

Pololi, L. Clay, M. C., Lipkin, M., Jr., Hewson, M., Kaplan, C., \& Frankel, R. M. (2001). Reflections on integrating theories of adult education into a medical school faculty development course. Medical Teacher, 23(3), 276-283. http://dx.doi.org/10.1080/ 01421590120043053

Postareff, L., Lindblom-Ylänne, S., \& Nevgi, A. (2007). The effect of pedagogical training on teaching in higher education. Teaching and Teacher Education, 23(5), 557-571. http://dx.doi.org/10.1016/j.tate.2006.11.013

Ramsden, P. (1998). Managing the effective university. Higher Education Research $\mathcal{E}^{\prime}$ Development, 17(3), 347-370. http://dx.doi.org/10.1080/0729436980170307

Rienties, B., \& Kinchin, I. M. (2014). Understanding (in)formal learning in an academic development programme: A social network perspective. Teaching and Teacher Education, 39, 123-135.

Roxå, T., Mårtensson, K., \& Alveteg, M. (2011). Understanding and influencing teaching and learning cultures at university: A network approach. Higher Education, 62(1), 99-111. http://dx.doi.org/10.1007/s10734-010-9368-9 
G Model

JSEE-553; No. of Pages 18

18

S. Van Was et al./Studies in Educational Evaluation $x x x$ (2015) $x x x-x x x$

Sasovova, Z., Mehra, A., Borgatti, S. P., \& Schippers, M. C. (2010). Network churn: The effects of self-monitoring personality on brokerage dynamics. Administrative Scionce Quarterly, 55(4), 639-670. http://dx.doi.org/10.2189/asqu.2010.55.4.639

Schoenfeld, A. C., \& Magnon, R. (1992). Mentor in a manual: Climbing the academic ladder to tenure. Madison, WI: Magna Publications.

Schrum, L., \& Ohler, J. (2005). Distance education at UAS: A case study. Journal of Distance Education, 20(1), 60-83.

Shah, P. P. (2000). Network destruction: The structural implications of downsizing. Academy of Management Journal, 43(1), 101-112. http://dx.doi.org/10.2307/ 1556389

Singer, J. D., \& Willet, J. B. (2003). Applied longitudinal data: Modeling change and event occurrence. New York: Oxford University Press.

Skeff, K. M., Stratos, G. A., Bergen, M. R., \& Regula, D. P. (1998). A pilot study of faculty development for basis science teachers. Academic Medicine, 73, 701-704.

Snijders, T. A. B. (2005). Models for longitudinal network data. In P. J. Carrington, J. Scott, \& S. Wasserman (Eds.), Models and methods in social network analysis (pp. 215-247). New York: Cambridge University Press.

Stepp-Greany, J. (2004). Collaborative teaching in an intensive Spanish course: A professional development experience for teaching assistants. Foreign Language Annals, 37(3), 417-424. http://dx.doi.org/10.1111/j.1944-9720.2004.tb02699.x

Stes, A., Clement, M., \& Van Petegem, P. (2007). The effectiveness of a faculty training programme: Long-term and institutional impact. International Journal for Academic Development, 12(2), 99-109. http://dx.doi.org/10.1080/13601440701604898

Ster, A., Min-Leliveld, M., Gijbels, D., \& Van Petegem, P. (2010). The impact of instructional development in higher education: The state-of-the-art of the research. Educational Research Review, 5(1), 25-49. http://dx.doi.org/10.1016/ j.edurev.2009.07.001

Stes, A., Coertjens, L., \& Van Petegem, P. (2013). Instructional development in higher education: Impact on teachers' teaching behaviour as perceived by students.
Instructional Science, 1(6), 1103-1126. http://dx.doi.org/10.1007/s11251-0139267-4

Stewart, M. (2014). Making sense of a teaching programme for university academics: Exploring the longer-term effects. Teaching and Teacher Education, 38, 89-98. http://dx.doi.org/10.1016/j.tate.2013.11.006

Strauss, A., \& Corbin, J. (1990). Basics of qualitative research: Grounded theory procedures and techniques. Newburg Park: Sage.

Taylor, L., \& Rage Colet, N. (2010). Making the shift from faculty development to educational development: A conceptual framework grounded in practice. In A. Saroyan \& M. Frenzy (Eds.), Building teaching capacities in higher education: A comprehensive international model. Sterling, VA: Stylus Publishing.

Trowler, P., \& Cooper, A. (2002). Teaching and learning regimes: Implicit theories and recurrent practices in the enhancement of teaching and learning through educetonal development programmes. Higher Education Research \& Development, 21(3), 221-240. http://dx.doi.org/10.1080/0729436022000020742

Van den Bossche, P., \& Segers, M. (2013). Transfer of training: Adding insight through social network analysis. Educational Research Review, 8, 37-47. http://dx.doi.org/ 10.1016/j.edurev.2012.08.002

Van Wees, S., Van den Bossche, P., Moolenaar, N. M., De Meyer, S., \& Van Petegem, P. (2015). Know-who? Linking faculty's networks to stages of instructional developmont. Higher Education. http://dx.doi.org/10.1007/s10734-015-9868-8

Warhurst, R. P. (2008). 'Cigars on the flight-deck': New lecturers' participatory learning within workplace communities of practice. Studies in Higher Education, 33(4), 453467. http://dx.doi.org/10.1080/03075070802211828

Wasserman, S., \& Faust, K. (1994). Social network analysis: Methods and applications. Cambridge: University Press.

Wright, E., \& Pescosolido, B. (2002). Sorry, I forgot: The role of recall error in longitudinal personal network studies. Advances in Medical Sociology, 8, 113-129. http:// dx.doi.org/10.1016/s1057-6290(02)80023-7

Please cite this article in press as: S. Van Wees, et al.. Uncovering changes in university teachers' professional networks during an instructional development program. Studies in Educational Evaluation (2015), http://dx.doi.org/10.1016/j.stueduc.2015.02.003 